\title{
Nonlinear Coupled Finite Element Analysis of A Dam-Reserviour Under Dynamic Loading
}

\author{
Dr. O. F. S. Al-Damluji Dr. A. Y. Th. Al-Sa'aty \\ Assist. Prof. / Civil Engg., Dept. \\ Prof./ Achreculter Dept. \\ University of Baghdad, Iraq. \\ Dr. R. M. Al-Nu' aimi \\ University of Mosul, Iraq. \\ Assist. Prof./ of Civil Engg. Dept., \\ University of Dohuk, Iraq.
}

\section{ABSTRACT}

This research presents a nonlinear coupled analysis of a dam-reserviour problem with aspects of class I coupling for fluid-structure interaction and class II coupling for soilpore fluid-structure interaction under earthquake excitations using finite element method. The analysis involves the compressibility of water, the flexibility of the dam, the earthquake excitation, the structural damping and the material nonlinearity on the response.

An efficient computer program is developed for this analysis from the original computer code named as MIXDYN. The new software for analyzing the coupled behaviour is established using the pressure formulation for modelling of fluid and the u$p$ formulation for modelling of soil-pore fluid.

Two differenent schemes for coupled field problems are implemented in the new computer code using the staggered partitioned solution technique in terms of sequential execution of single-field analyzers. Eight-nodded two-dimensional isoparametric element is adopted for idealization each of soil, fluid and structure. The Drucker Prager model is used to simulate the behavior of soil and concrete. Implicit-Implicit Newmark's scheme with corrector predictor algorithm is employed for time integration of the equations of motion. The capability and the efficiency of the model are found to be very useful.

Keywords: Coupled analysis, dam-reserviour, finite element method, fluid-structure interaction, soil-pore-fluid interaction, pressure formulation, u-p formulation.

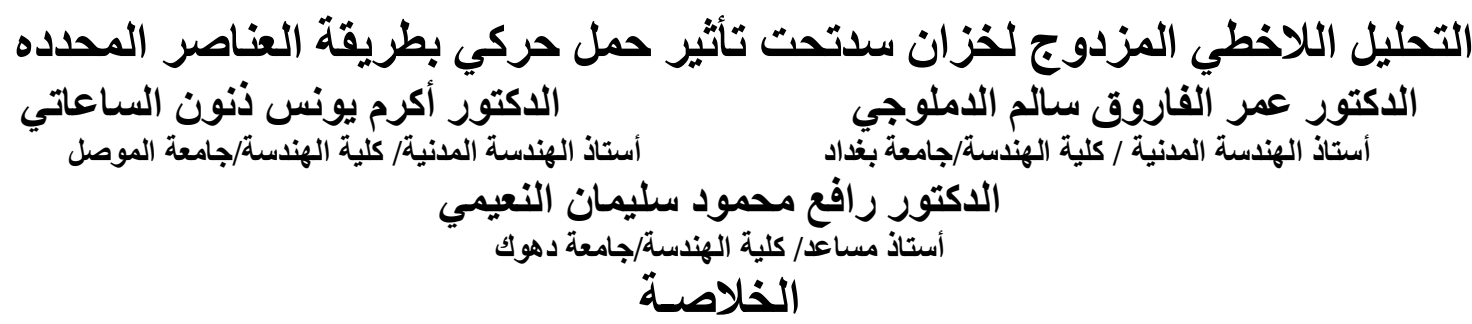

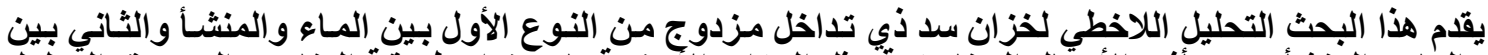

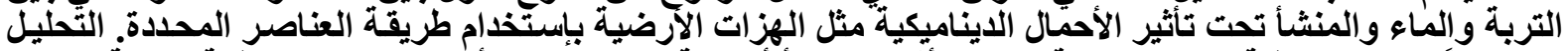

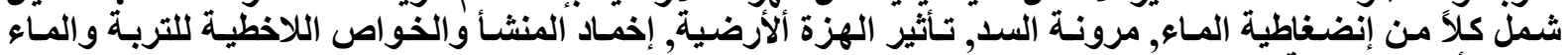

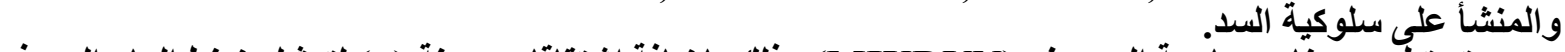

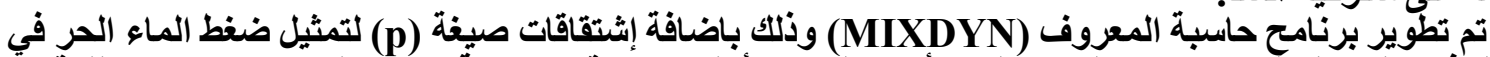

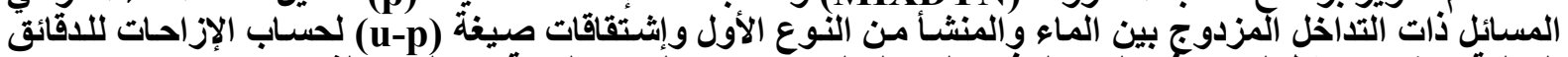

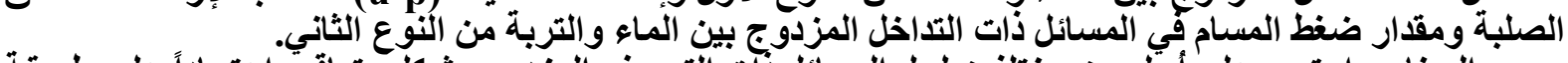

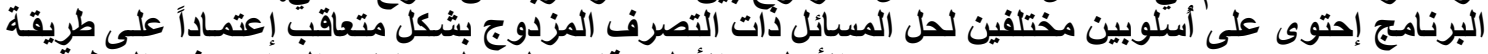

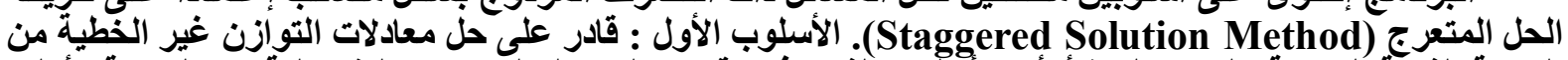

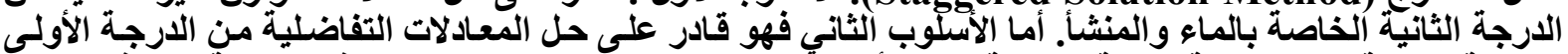

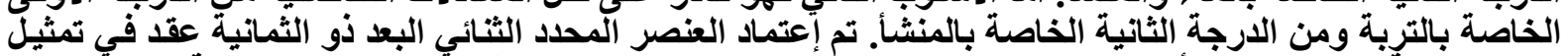

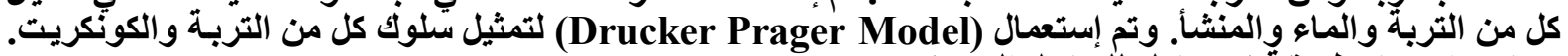

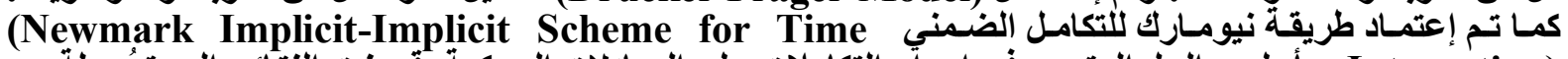
Integration)

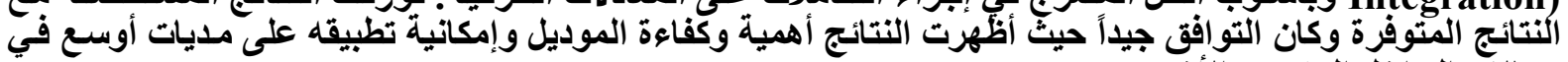
مجالات التداخل المزدوج الأخرى.

Received: $\mathbf{2 8}-\mathbf{1 2} \mathbf{- 2 0 0 9}$

Accepted: $29-12-2011$ 


\section{Introduction}

The dynamic analysis of soil-fluid-structure interaction includes all aspects of both fluid and solid mechanics. In fluid-phase, viscosity of the fluid, magnitude of the gradient of the velocity field throughout the flow and whether the fluid is (compressible or incompressible), depending on whether density variations are large or small, play a key role in choosing the kind of formulation to be used. While in the solid-phase, the time scale and the solver algorithm to be used depends on the loading rate and the permeability of the porous medium. Traditionally, fluid problems can be classified into two categories: (i) non-flow problems, such as impounded water in a reservoir, tank, etc.. and (ii) flow problems, such as free surface flow, flow around an airfoil etc.... In this study, the former type of problems is considered.

The second class of problems to be considered here lies between the undrained and drained extremes where dynamic loading is applied and transient pore-fluid motion is significant [26]. The undrained analysis is possible when relatively rapid loads are applied and permeability is low, i.e., where the load rate is greater than the pore fluid diffusion rate. Otherwise, drained analysis is possible for situations with a relatively slow loading and high permeability. Consequently, the problem to be solved in this research being a triple interaction: fluid-structure-soil pore fluid.

\subsection{Fluid-Structure Interaction (Class I Coupling)}

The dynamic interaction between an elastic structure and a fluid has been the subject of intensive investigations, e.g. ([7], [13], [22], [23], and [25]). Many researchers have attempted to derive variational functionals for different classes of fluid-structure interaction problems, e.g. ([13], and [29]). Others have attempted to reduce the problem size in different ways, such as boundary integral technique, Ritz and Eigen vectors along with a combination of finite element and boundary element methods. Several finite element studies have considered the gravity and free surface effects along with the fluid structure interaction, e.g. ([1], and [28]).

Out of all the works done in the area of developing a finite element method for fluidstructure interaction problems, two approaches predominate. The first approach is the displacement-based method where the displacements are the nodal variables in both the fluid and the structure ([5], and [14]). However, this approach is not well suited for problems with large fluid displacements and special care must be taken to prevent zero-energy rotational modes from arising. The second approach is the potential-based method, where displacements remain as nodal variables in the structure, but velocity potentials or pressures are unknowns in the fluid ([6], [17] and [31]).

\subsection{Soil-Pore Fluid-Structure Interaction (Class II Coupling)}

Soils are multiphase materials exhibiting a strong mechanical coupling between the solid skeleton and the fluid phase. This coupling can be particularly strong in the case of saturated soils of low permeability and fast transient or dynamic loading, where pore pressure plays a significant role. The first successful attempt to develop a model for solid skeleton-pore fluid interaction was due to Biot [3, and 4] for linear elastic materials. This work was followed by further development at Swansea University, where Zienkiewicz et al. ([33], [34], [35], [36]) extended the theory to non-linear materials and large deformation problems.

Pastor and Merodo [19] used finite element method in the frequency domain based on displacements and pore pressures as main variables. Their formulation was limited for linear models, with incompressible pore fluid and very small permeability. The results of quay wall 
analysis under dynamic loading show that incompressibility of pore fluid may result in volumetric locking of the mesh with a severe loss of accuracy.

Nogami and Kazama [15] developed a three-dimensional thin layer element method for dynamic soil-structure interaction analysis of axi-symmetric structures in submerged soil. Their formulation was based on Biot's wave equation. The results show that the submerged condition affects the characteristics of the Rayleigh waves in soil, alters the soil-structure interaction stresses if the permeability of the soil is relatively large and, to less extent, the response of the structure.

Spyrakos and $\mathrm{Xu}$ [27] developed a seismic analysis of intake-outlet towers including soilstructure-water interaction. Their formulation considers the effect of partial soil-foundation separation and the hydrodynamic pressure of the water through added masses. The results show that hydrodynamic effects are significant and cause an increase in deflections, moments and shears and a decrease in foundation rotation.

Guan and Moore [9] performed a dynamic analysis in a frequency domain of reservoirdam systems resting on a multi-layered soil when subjected to El-Centro earthquake ground motion (1940). The impounded fluid was assumed viscous and the dam was modelled using the finite element method. The stiffness matrix of the layered soil was obtained by means of the layer transfer matrix.

Zienkiewicz [30], and Park and Felippa [18] described extensively several kinds of coupled problems and their numerical solution with some applications. It was found that the non-linear soil response causes a pore pressure build up and failure of the actual structure. Also, the resulting matrices after semi-discretization are found to be not symmetric and therefore, stabilization at the differential equation level before attempting to implement a partitioned solution procedure is necessary.

\section{The Governing Equations of Fluid Dynamics}

\subsection{The Fluid Model}

In the fluid-solid models, the following assumptions are made: (1) the fluid is linear, compressible and inviscid, (2) the flow is considered irrotational, (3) there is no friction between the fluid and solid (no boundary layer), (4) thermal effects are negligible and (5) the solid may undergo plastic deformations.

The stress-strain relations for a linear, isotropic fluid require the definition of two constants [32]. The first of these links the deviatoric stresses to the deviatoric strain rates:

$\tau_{\mathrm{ij}}=\sigma_{\mathrm{ij}}-\delta_{\mathrm{ij}} \sigma_{\mathrm{kk}} / 3=2 \mu^{\prime}\left(\dot{\varepsilon}_{\mathrm{ij}}-\delta_{\mathrm{ij}} \dot{\varepsilon}_{\mathrm{kk}} / 3\right)$

where: $\delta_{\mathrm{ij}}=$ Kronecker's delta,

$\mu^{\prime}=$ Dynamic viscosity,

$\sigma_{\mathrm{kk}}=\sigma_{11}+\sigma_{22}+\sigma_{33}$, and

$\dot{\varepsilon}_{\mathrm{kk}}=\dot{\varepsilon}_{11}+\dot{\varepsilon}_{22}+\dot{\varepsilon}_{33}$

The second relation is that between the mean stress changes and the volumetric strain rates. This defines the pressure as:

$\mathrm{P}=\sigma_{\mathrm{ii}} / 3=\mathrm{k} \dot{\varepsilon}_{\mathrm{kk}}-\mathrm{P}_{\mathrm{o}}$

where: $\mathrm{k}=$ the volumetric viscosity.

$\mathrm{P}_{\mathrm{o}}=$ the initial hydrostatic pressure independent of the strain rate.

Moderate fluid motion can be considered linear and the constitutive law is given by:

$\varepsilon_{\mathrm{V}}=-\mathrm{P} / \mathrm{K}$

where: $\varepsilon_{\mathrm{V}}=$ the volumetric strain,

$\mathrm{P}=$ the pressure above the hydrostatic value, and

$\mathrm{K}=$ the bulk modulus of the fluid. 


\subsection{Mass Conservation}

This is also known as the continuity condition. Using the concept of control volume, the principle of conservation of mass in three dimensions is expressed as [8]:

$\dot{\rho}_{\mathrm{f}}+\left(\rho_{\mathrm{f}} \underline{\dot{\mathrm{u}}}_{\mathrm{i}}\right)_{\mathrm{i}_{\mathrm{i}}}=0 \equiv \dot{\rho}_{\mathrm{f}}+\underline{\nabla}\left(\rho_{\mathrm{f}} \underline{\dot{\mathrm{u}}}\right)$

or

$\partial \rho_{f} / \partial t+\partial\left(\rho_{f} \dot{\mathbf{u}}_{\mathbf{x}}\right) / \partial x+\partial\left(\rho_{f} \dot{\mathbf{u}}_{\mathbf{y}}\right) / \partial y+\partial\left(\rho_{f} \dot{\mathbf{u}}_{\mathbf{z}}\right) / \partial z=0$

where: $\rho_{\mathrm{f}}=$ the mass density, $\underline{\mathrm{u}}=\hat{\mathrm{i}} \dot{\mathrm{u}}_{\mathrm{x}}+\hat{\mathrm{j}} \dot{\mathrm{u}}_{\mathrm{y}}+\hat{\mathrm{k}} \dot{\mathrm{u}}_{\mathrm{z}}, \hat{\mathrm{i}}, \hat{\mathrm{j}}, \hat{\mathrm{k}}=$ the unit vectors in $\mathrm{x}, \mathrm{y}$ and $\mathrm{z}$ directions, respectively, $\underline{\nabla}=\hat{\mathrm{i}}(\partial / \partial \mathrm{x})+\hat{\mathrm{j}}(\partial / \partial \mathrm{y})+\hat{\mathrm{k}}(\partial / \partial \mathrm{z}), \mathrm{t}=$ the time, and $\dot{\mathrm{u}}_{\mathrm{x}}, \dot{\mathrm{u}}_{\mathrm{y}}$ and $\dot{\mathrm{u}}_{\mathrm{Z}}=$ the velocity components (for the fluid) in $\mathrm{x}, \mathrm{y}$ and $\mathrm{z}$ directions, respectively.

If the changes in the fluid density are small (i.e., $\dot{\rho}_{\mathrm{f}}$ is small), Equation (4) reduces to:

$\dot{\mathrm{u}}_{\mathrm{i}, \mathrm{i}}=\varepsilon_{\mathrm{V}}=-\mathrm{P} / \mathrm{K}$

\subsection{Momentum Conservation}

The momentum equation for the fluid is expressed as [8]:

$\rho_{\mathrm{f}}\left(\mathrm{D} \dot{\mathrm{u}}_{\mathrm{i}} / \mathrm{Dt}\right)=\sigma_{\mathrm{ij}, \mathrm{j}}+\rho_{\mathrm{f}} \mathrm{g}_{\mathrm{i}}$

where

$\mathrm{D} \dot{\mathrm{u}}_{\mathrm{i}} / \mathrm{Dt}=\ddot{\mathrm{u}}_{\mathrm{i}}+\dot{\mathrm{u}}_{\mathrm{i}, \mathrm{j}} \dot{\mathrm{u}}_{\mathrm{j}} \approx \ddot{\mathrm{u}}_{\mathrm{i}}$

For small motion, the term $\dot{\mathrm{u}}_{\mathrm{i}, \mathrm{j}} \dot{\mathrm{u}}_{\mathrm{j}}$ (as compared to $\ddot{\mathrm{u}}_{\mathrm{i}}$ ) is negligible. If the stresses and pressures are taken as the excess above the hydrostatic pressure, then the body forces can be neglected. For small displacements, the constitutive law for stresses is defined as [8]:

$\sigma_{\mathrm{ij}}=-\mathrm{P}\left(\rho_{\mathrm{f}}\right) \delta_{\mathrm{ij}}-\mu^{\prime}\left[(2 / 3) \delta_{\mathrm{ij}} \dot{\varepsilon}_{\mathrm{kk}}-2 \dot{\varepsilon}_{\mathrm{ij}}\right]$

in which, $\dot{\varepsilon}_{\mathrm{ij}}=\left(\dot{\mathrm{u}}_{\mathrm{i}, \mathrm{j}}+\dot{\mathrm{u}}_{\mathrm{j}, \mathrm{i}}\right) / 2$ and $\mu^{\prime}=$ the dynamic viscosity.

Substitution of Equations (7) and (8) in Equation (6) gives:

$\rho_{\mathrm{f}} \ddot{\mathrm{u}}_{\mathrm{i}}=-\mathrm{P}, \mathrm{i}-\mu^{\prime}\left[(2 / 3) \dot{\mathrm{u}}_{\mathrm{k}, \mathrm{ki}}-\dot{\mathrm{u}}_{\mathrm{i}, \mathrm{kk}}\right]$

and if the viscosity is neglected, one can get:

$\rho_{\mathrm{f}} \ddot{\mathrm{u}}_{\mathrm{i}}=-\mathrm{P}, \mathrm{i}$

For an incompressible flow, the volume change is zero $\left(\varepsilon_{\mathrm{V}}=0\right)$. Therefore, Equation (5) reduces to:

$\dot{\mathrm{u}}_{\mathrm{i}, \mathrm{i}}=0$

and for $\dot{\mathrm{u}}_{\mathrm{k}, \mathrm{k}}=0$. Equation (9) reduces to:

$\rho_{\mathrm{f}} \ddot{\mathrm{u}}_{\mathrm{i}}=-\mathrm{P}, \mathrm{i}+\mu^{\prime} \dot{\mathrm{u}}_{\mathrm{i}, \mathrm{kk}}$

\subsection{Governing Equation of Motion}

Eliminating $\mathrm{u}$ from Equations (5) and (9) gives the following well-known wave Equation [11]:

$\nabla^{2} \mathrm{P}+\xi^{\prime} \nabla^{2} \dot{\mathrm{P}}=\ddot{\mathrm{P}} / \mathrm{c}^{2}$ (Linearized-Navier-Stokes Equation) 
where: $\xi^{\prime}=4 \mu^{\prime} / 3 \rho_{\mathrm{f}} \mathrm{c}^{2}, \mu^{\prime}=$ the dynamic viscosity of fluid and $\mathrm{c}^{2}=\mathrm{K} / \rho$.

For an inviscid fluid, Equation (13) reduces to:

$\nabla^{2} \mathrm{P}=\ddot{\mathrm{P}} / \mathrm{c}^{2}$

\subsection{Boundary Condition}

(i) At moving boundaries (at interface with solid) where the fluid has a normal acceleration, $\ddot{\mathrm{u}}_{\mathrm{n}}, \mathrm{n}$ being the direction of the unit normal to the boundary, the pressure gradient can be expressed as:

$\partial \mathrm{P} / \partial \mathrm{n}=-\rho_{\mathrm{f}} \ddot{\mathrm{u}}_{\mathrm{n}}$

At fixed boundaries; $\partial \mathrm{P} / \partial \mathrm{n}=0$.

(ii) At a free surface with surface waves (considering only primary waves):

$\mathrm{P}=\rho_{\mathrm{f}} \mathrm{g} \mathrm{u}_{\mathrm{y}} \quad$ or $\quad \partial \mathrm{P} / \partial \mathrm{y}=\ddot{\mathrm{p}} / \mathrm{g}$

At a free surface without surface waves: $\mathrm{P}=0$.

(iii) At radiating boundaries, the condition for no reflection of pressure waves can be expressed as:

$\partial \mathrm{P} / \partial \mathrm{n}=-\dot{\mathrm{P}} / \mathrm{c}$

where: $\mathrm{n}=$ the direction of the unit normal at the radiating boundary.

\section{Fluid-Structure Interaction (Pressure Formulation)}

The structure and fluid are together idealized as a two dimensional system subjected to excitation both in the horizontal and vertical directions. The fluid domain is represented by 8 nodes finite elements with one degree of freedom per node. This degree of freedom is the value of the pressure $\mathrm{P}$ at the nodes. At the free surface, the element has an extra translational degree of freedom to accommodate the free surface motion. The equations of motion can be expressed, after spatial discretization, by two sets of second order coupled differential equations. The fluid can be modeled using either the displacement, or displacement potential, or velocity potential, or pressure formulations. However, in this study only the pressure formulation is used because it results in fewer unkowns. The coupled fluid-structure equations can be expressed as:

$\underline{\mathrm{M}}_{\mathrm{s}} \underline{\ddot{\mathrm{u}}}+\underline{\mathrm{C}}_{\mathrm{s}} \underline{\dot{\mathbf{u}}}+\underline{\mathrm{K}}_{\mathrm{s}} \underline{\mathrm{u}}=\underline{\mathrm{f}}_{\mathrm{s}}-\underline{\mathrm{M}}_{\mathrm{s}} \ddot{\mathrm{d}}+\underline{\mathrm{L}} \underline{\mathrm{P}}$

$\underline{M_{\mathrm{f}}} \underline{\ddot{\mathrm{P}}}+\underline{\mathrm{C}}_{\mathrm{f}} \underline{\dot{\mathrm{P}}}+\underline{\mathrm{K}}_{\mathrm{f}} \underline{\mathrm{P}}=\underline{\mathrm{f}}_{\mathrm{f}}-\rho_{\mathrm{f}} \underline{\mathrm{L}}^{\mathrm{T}}(\underline{\ddot{\mathbf{i}}}+\underline{\ddot{\mathbf{d}}})$

where:

$\underline{\mathrm{M}}_{\mathrm{s}}=\int_{\Omega} \underline{\mathrm{N}}_{\mathrm{u}}^{\mathrm{T}} \rho \underline{\mathrm{N}}_{\mathrm{u}} \mathrm{d} \Omega$

$\underline{\mathrm{C}}_{\mathrm{s}}=\alpha \underline{\mathrm{M}}_{\mathrm{s}}+\beta \underline{\mathrm{K}}_{\mathrm{s}}$ (Rayleigh Damping)

$\underline{\mathrm{K}}_{\mathrm{s}}=\int_{\Omega} \underline{\mathrm{B}}^{\mathrm{T}} \underline{\mathrm{D}}_{\mathrm{T}} \underline{\mathrm{B}} \cdot \mathrm{d} \Omega$

$\underline{\mathrm{f}}_{\mathrm{s}}=\int_{\Gamma \mathrm{u}} \underline{\mathrm{N}}_{\mathrm{u}}^{\mathrm{T}} \underline{\mathrm{t}} \mathrm{d} \Gamma+\int_{\Omega} \underline{\mathrm{N}}_{\mathrm{u}}^{\mathrm{T}} \rho \underline{\mathrm{b}} \mathrm{d} \Omega+\int_{\Omega} \underline{B}^{\mathrm{T}} \underline{\mathrm{D}}^{\mathrm{T}} \mathrm{d} \underline{\varepsilon}^{\mathrm{o}} \mathrm{d} \Omega$

$\underline{L}=\int_{\Omega} \alpha_{\mathrm{c}} \underline{\mathrm{B}}^{\mathrm{T}} \underline{\delta} \underline{\mathrm{N}}_{\mathrm{p}} \mathrm{d} \Omega$

$\left(\underline{\mathrm{M}}_{\mathrm{f}}\right)_{\mathrm{ij}}=\int_{\Gamma \mathrm{F}} \underline{\mathrm{N}}_{\mathrm{pi}} 1 / \mathrm{g} \underline{\mathrm{N}}_{\mathrm{pj}} \mathrm{d} \Gamma+\int_{\Omega \mathrm{F}} \underline{\mathrm{N}}_{\mathrm{pi}}^{\mathrm{T}} 1 / \mathrm{c}^{2} \underline{\mathrm{N}}_{\mathrm{pj}} \mathrm{d} \Omega$ 


$$
\begin{aligned}
& \left(\underline{\mathrm{C}}_{\mathrm{f}}\right)_{\mathrm{ij}}=\int_{\Gamma \mathrm{R}} \underline{\mathrm{N}}_{\mathrm{pi}}^{\mathrm{T}} 1 / \mathrm{c}^{2} \underline{\mathrm{N}}_{\mathrm{pj}} \mathrm{d} \Gamma \\
& \left(\underline{\mathrm{K}}_{\mathrm{f}}\right)_{\mathrm{ij}}=\int_{\Omega \mathrm{F}}\left(\nabla \underline{\mathrm{N}}_{\mathrm{pi}}\right)^{\mathrm{T}}\left(\nabla \underline{\mathrm{N}}_{\mathrm{pj}}\right) \mathrm{d} \Omega \\
& \left(\underline{\mathrm{L}}^{\mathrm{T}}\right)_{\mathrm{ij}}=\int_{\Gamma \mathrm{I}} \underline{\mathrm{N}}_{\mathrm{ui}}^{\mathrm{T}} \mathrm{n} \underline{\mathrm{N}}_{\mathrm{pj}} \mathrm{d} \Gamma
\end{aligned}
$$

\section{Pore Fluid-Solid Interaction (u-p Formulation)}

When the seepage velocity relative to the solid skeleton is small compared with the motion of the solid skeleton or if the permeability is low, the relative acceleration of the fluid with respect to the solid can be neglected. With this approximation (i.e., neglecting the $\ddot{\mathbf{w}}$ term) and replacing the unknown $\mathrm{w}$ with the pressure $\mathrm{P}$, the equilibrium equation of the fluid can be rewritten as [20]:

$\underline{\dot{\mathrm{w}}}=-\mathrm{k} \underline{\nabla} \mathrm{P}+\mathrm{k} \rho \underline{b}-\mathrm{k} \rho \underline{\ddot{\mathrm{u}}}$

which can be used to eliminate $\mathrm{w}$ from the continuity equation. Upon discretization, it is possible to write:

$\underline{\mathrm{u}}=\underline{\mathrm{N}}_{\mathrm{u}} \underline{\mathrm{u}}$

$\underline{\mathrm{P}}=\underline{\mathrm{N}_{\mathrm{p}}} \mathrm{P}$

and using the standard Gelerkin method, the resulting equations can be expressed as:

$\underline{\mathrm{M}}_{\mathrm{s}} \underline{\ddot{\mathrm{u}}}+\underline{\mathrm{C}}_{\mathrm{s}} \underline{\dot{\mathrm{u}}}+\underline{\mathrm{K}}_{\mathrm{s}} \underline{\mathrm{u}}=\underline{\mathrm{f}}_{\mathrm{s}}-\underline{\mathrm{M}}_{\mathrm{s}} \underline{\ddot{\mathrm{d}}}+\underline{\mathrm{L}} \underline{\mathrm{P}}$

$\underline{\mathrm{C}}_{\mathrm{P}} \underline{\dot{\mathrm{P}}}+\underline{K}_{\mathrm{P}} \underline{\mathrm{P}}=\underline{\mathrm{f}}_{\mathrm{P}}-\underline{\mathrm{L}}^{\mathrm{T}} \underline{\dot{\mathrm{u}}}+\underline{\hat{\mathrm{M}}} \underline{\mathrm{u}}$

where:

$\underline{\mathrm{M}}_{\mathrm{s}}=\int_{\Omega} \underline{\mathrm{N}}_{\mathrm{u}}^{\mathrm{T}} \rho \underline{\mathrm{N}}_{\mathrm{u}} \mathrm{d} \Omega$

$\underline{\mathrm{C}}_{\mathrm{s}}=\alpha \underline{\mathrm{M}}_{\mathrm{s}}+\beta \underline{\mathrm{K}}_{\mathrm{s}}$

(Rayliegh Damping)

$\underline{\mathrm{K}}_{\mathrm{s}}=\int_{\Omega} \underline{\mathrm{B}}^{\mathrm{T}}\left(\underline{\mathrm{D}}_{\mathrm{T}}+\alpha_{\mathrm{c}}^{2} \delta \cdot \mathrm{Q} \cdot \delta^{\mathrm{T}}\right) \underline{\mathrm{B}} \cdot \mathrm{d} \Omega$

$\underline{\mathrm{f}}_{\mathrm{s}}=\int_{\Gamma \mathrm{u}} \underline{\mathrm{N}}_{\mathrm{u}}^{\mathrm{T}} \underline{\mathrm{t}} \mathrm{d} \Gamma+\int_{\Omega} \underline{\mathrm{N}}_{\mathrm{u}}^{\mathrm{T}} \rho \underline{\mathrm{b}} \mathrm{d} \Omega+\int_{\Omega} \underline{\mathrm{B}}^{\mathrm{T}} \underline{\mathrm{D}}^{\mathrm{T}} \mathrm{d} \underline{\varepsilon}^{\mathrm{o}} \mathrm{d} \Omega$

$\underline{L}=\int_{\Omega} \alpha_{\mathrm{c}} \underline{\mathrm{B}}^{\mathrm{T}} \underline{\delta} \underline{\mathrm{N}}_{\mathrm{p}} \mathrm{d} \Omega$

$\underline{\mathrm{C}}_{\mathrm{p}}=\int_{\Omega} \underline{\mathrm{N}}_{\mathrm{P}}^{\mathrm{T}} 1 / \mathrm{Q} \underline{\mathrm{N}}_{\mathrm{p}} \mathrm{d} \Omega$

$\underline{\mathrm{K}}_{\mathrm{p}}=\int_{\Omega}\left(\nabla \underline{\mathrm{N}}_{\mathrm{P}}\right)^{\mathrm{T}} \mathrm{k}\left(\nabla \underline{\mathrm{N}}_{\mathrm{p}}\right) \mathrm{d} \Omega$

$\underline{f}_{\mathrm{p}}=\int_{\Gamma \mathrm{p}} \underline{\mathrm{N}}_{\mathrm{P}}^{\mathrm{T}} \mathrm{P} \mathrm{d} \Gamma+\int_{\Omega}\left(\nabla \underline{\mathrm{N}}_{\mathrm{P}}\right)^{\mathrm{T}} \mathrm{k} \rho_{\mathrm{f}} \underline{\mathrm{b}} \mathrm{d} \Omega$

$\underline{\mathrm{L}}^{\mathrm{T}}=\int_{\Omega} \alpha_{\mathrm{c}} \underline{\mathrm{N}}_{\mathrm{p}}^{\mathrm{T}} \underline{\delta} \underline{\mathrm{B}} \mathrm{d} \Omega$

$\underline{\hat{\mathrm{M}}}=\int_{\Omega}\left(\nabla \underline{\mathrm{N}}_{\mathrm{P}}\right)^{\mathrm{T}} \mathrm{k} \rho_{\mathrm{f}} \underline{\mathrm{N}}_{\mathrm{u}} \mathrm{d} \Omega$

where: $\underline{N}_{p}$ and $\underline{N}_{u}$ are the shape functions used for pore pressure and solid skeleton, respectively. $\alpha$ and $\beta$ are Rayliegh damping constants, $\Omega=$ the domain, $\Gamma=$ the boundary surface, $\underline{\mathrm{B}}=$ the strain displacement matrix and $\mathrm{t}=$ the surface traction. In this study, this formulation is implemented and used in the computer program. 


\section{Staggered Solution for Coupled-Field Problems}

Many engineering problems are generally partitioned into well defined fields which are distinct in behaviour, material model or solution technique. Each field may be coupled (totally or partially) with other participating fields or with only few of them (at interfaces via the contact boundaries only).

The concept of staggered solution can be organized in terms of sequential execution of single-field analyzers. This leads in the nodal based implicit-explicit partitioning of time stepping, to a complete solution of the explicit scheme independently of the implicit one and then using the results to progress with the implicit partition. This approach offers several advantages over the field elimination and simultaneous solution approaches [32]. Therefore in this study, the staggered partitioned solution scheme as shown in Figure (1) is implemented and used in the new computer code.

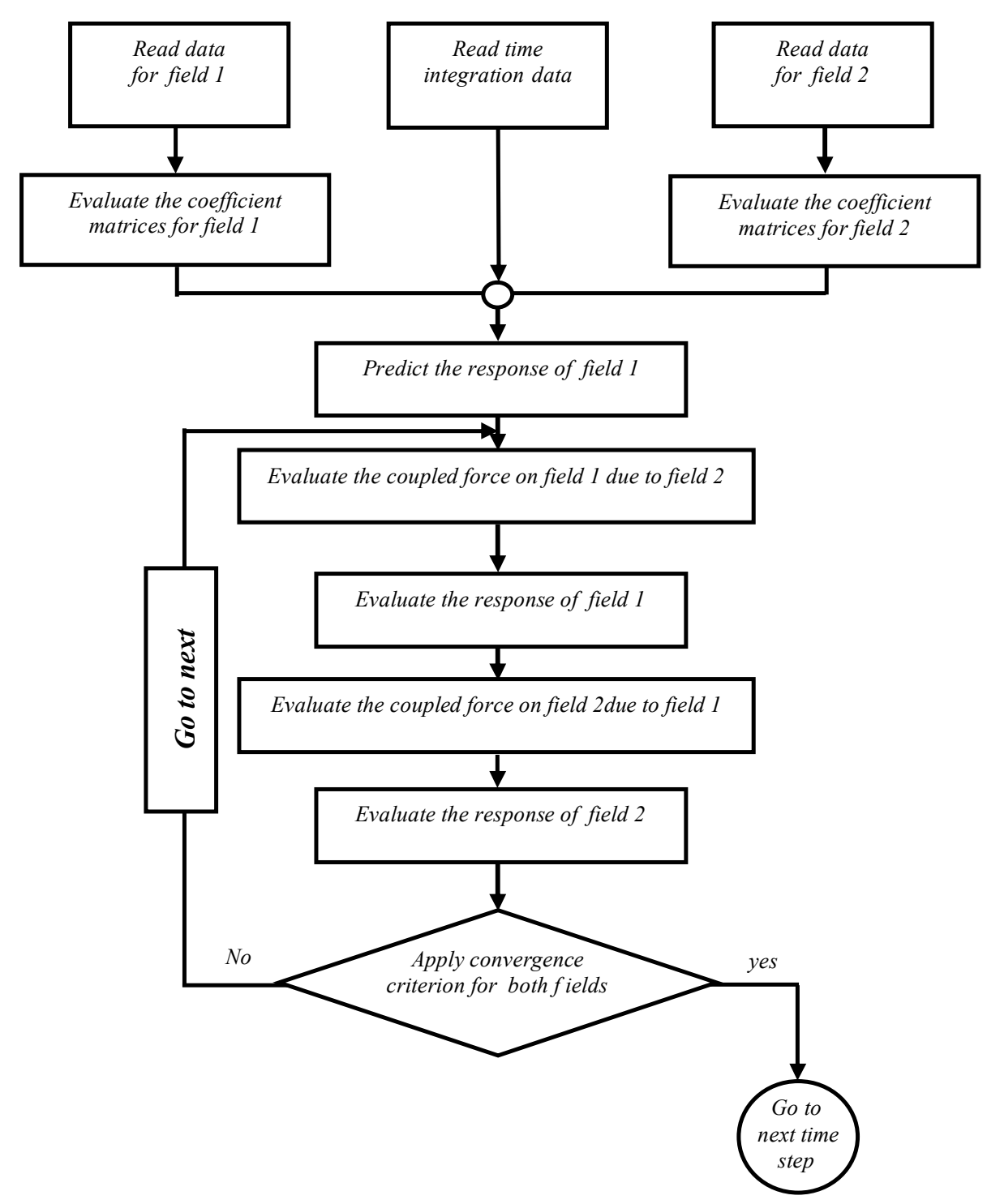

Figure (1): Staggered partitioned solution scheme for coupled field problem. 


\subsection{Solution Procedure for Class I and Class II Couplings}

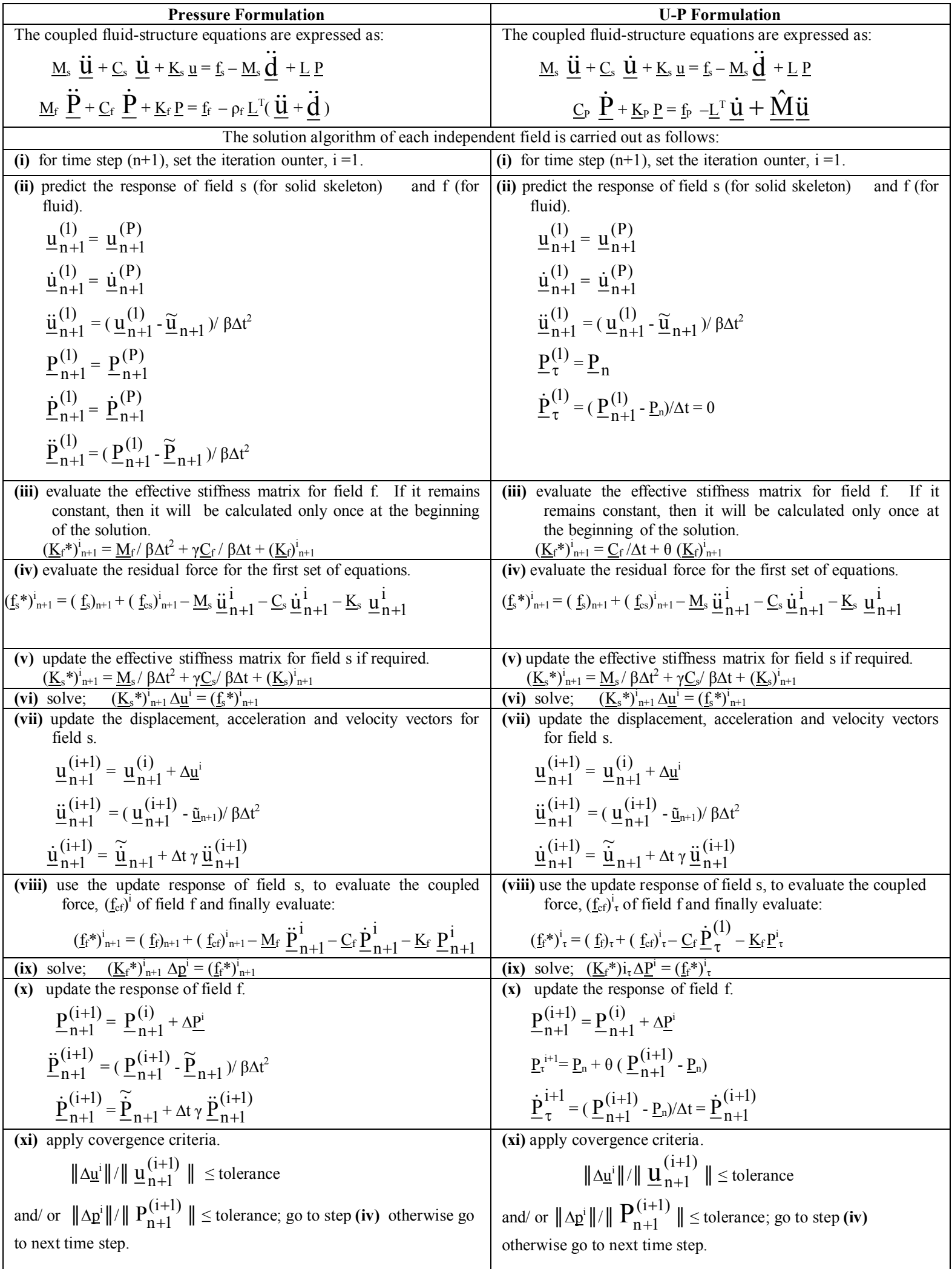

where : $\left\|\Delta \underline{u}^{\mathrm{i}}\right\|$ is the norm of incremental $\underline{\mathrm{u}}$ in ith iteration. ; $\left\|\underline{\mathrm{u}}_{\mathrm{n}+1}^{(\mathrm{i}+1)}\right\|$ is the norm of current total $\underline{\mathrm{u}}$. $\left\|\Delta \underline{\mathrm{P}}^{\mathrm{i}}\right\|$ is the norm of incremental $\underline{\mathrm{P}}$ in ith iteration; $\left\|\underline{\mathrm{P}}_{\mathrm{n}+1}^{(\mathrm{i}+1)}\right\|$ is the norm of current total $\underline{\mathrm{P}}$. 


\section{Numerical Example: Dam-reserviour system}

The Koyna concrete gravity dam-reservoir system is analyzed with all the aspects of fluidstructure interaction (class I coupling) and soil-pore-fluid interaction (class II coupling). The shape and dimensions of the dam-reservoir system are shown in Figure (2). The material properties of the system are taken from Al-Nu' aimi [2] and listed in Table (1). The analysis involves the compressibility of water, the flexibility of the dam, the structural damping, the earthquake excitations and structural nonlinearity on the response. This problem is solved by [20] as a fluid-structure interaction (i.e., with class I coupling) only.

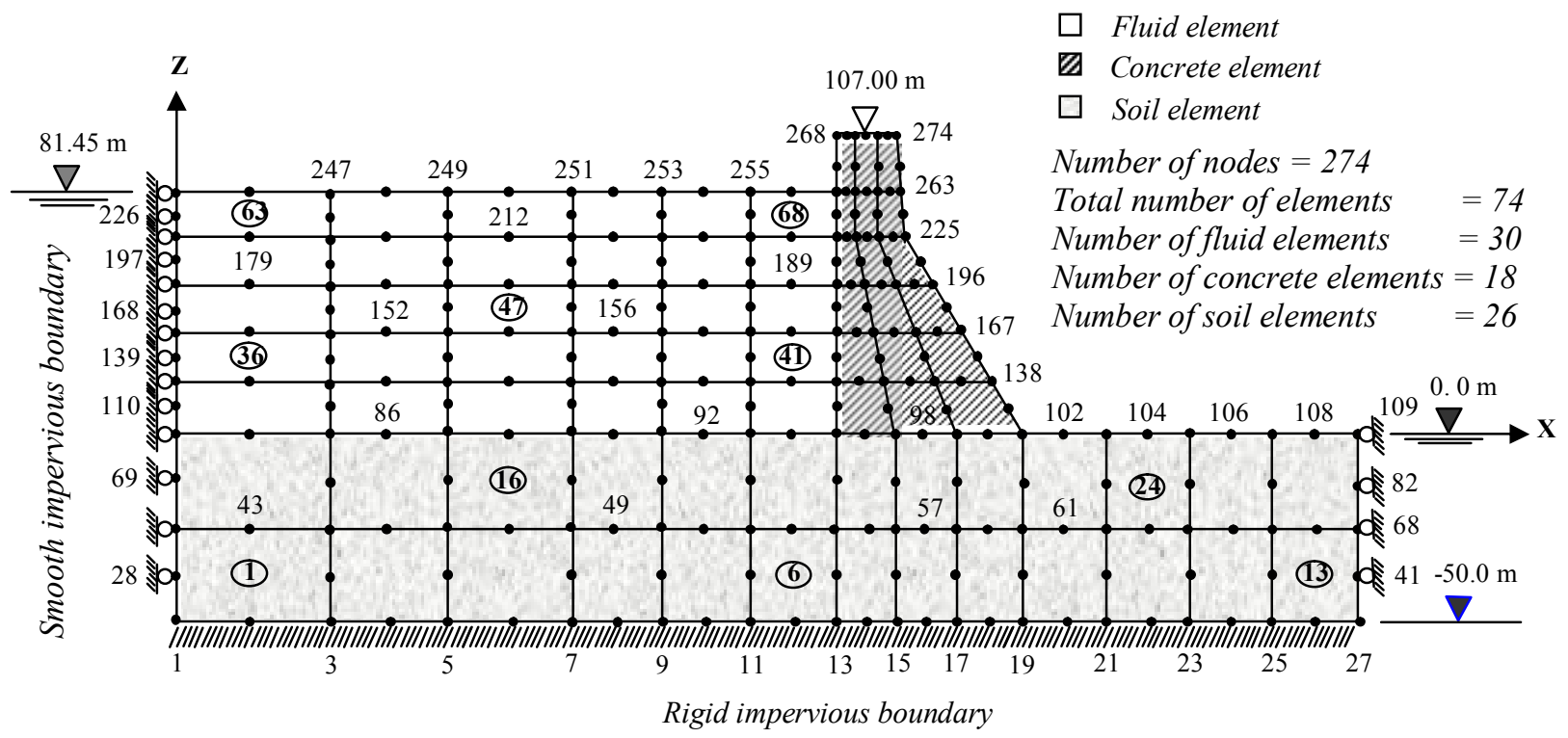

Figure (2): Koyna dam-reservoir system (India).

Table (1): Dimensions and properties of Koyna dam-reservoir system (Al-Nu' aimi [2]).

\begin{tabular}{|c|c|}
\hline Material and Property & Value \\
\hline 1. Dam (concrete) & 107.00 \\
\hline Height of dam above foundation $(\mathrm{m})$. & 81.45 \\
\hline Depth of reservoir $(\mathrm{m})$. & 3164000 \\
\hline Young's modulus of concrete, $\mathrm{E}_{\mathrm{c}}\left(\mathrm{T} / \mathrm{m}^{2}\right)$ & 0.20 \\
\hline Poisson's ratio of concrete, $v_{\mathrm{c}}$ & 2.690 \\
\hline Density of concrete, $\rho_{\mathrm{c}}\left(\mathrm{T} / \mathrm{m}^{3}\right)$ & 1800000 \\
\hline 2. Soil (rock) & 0.20 \\
\hline Young's modulus of soil, $\mathrm{E}\left(\mathrm{T} / \mathrm{m}^{2}\right)$ & 1.830 \\
\hline Poisson's ratio of soil, $v_{\mathrm{s}}$ & 1439.0 \\
\hline Density of soil, $\rho_{\mathrm{s}}\left(\mathrm{T} / \mathrm{m}^{3}\right)$ & 1.000 \\
\hline 3. Fluid $(\mathbf{w a t e r})$ & \\
\hline Compressibility of water, $\mathrm{c}(\mathrm{m} / \mathrm{sec})$ & 0.566 \\
\hline Density of water, $\rho_{\mathrm{f}}\left(\mathrm{T} / \mathrm{m}^{3}\right)$ & \\
\hline $\begin{array}{c}\text { The ratio of fundamental periods of reservoir } \\
\text { to the dam: }\end{array}$ & \\
\hline $\begin{array}{c}\gamma_{\mathrm{T}}=\left(\mathrm{T}_{\mathrm{f}}\right) \text { reservoir }\left(\mathrm{T}_{\mathrm{f}}\right) \mathrm{dam} \\
\end{array}$ & \\
\hline
\end{tabular}




\subsection{Results and Disscussion \\ 6.1.1 Effect of Water Compressibility}

For this study, the rigid Koyna dam is subjected to a horizontal Heaviside unit base excitation. The velocity of water is taken as a measure of water compressibility $\left(K=c^{2} \rho_{f}\right)$. Figure (3) shows the pressure distribution for cases with incompressible and compressible water. It is observed that as the velocity of water is increased from $1 \mathrm{c}$ to $4 \mathrm{c}$, the peak hydrodynamic force does not change significantly. But, there is a shift in the occurrence of the peak force. This implies that the compressibility of water has a significant effect on the distribution of pressure on the rigid dam.

\subsubsection{Effect of Dam Flexibility}

Again, the rigid Koyna dam is subjected to a horizontal Heaviside unit base excitation. The pressure distribution for several cases of dam-foundation flexibilities are shown in Figure (4). For the case of dam on a flexible foundation, as the flexibility of the dam system increases (by decreasing its modulus of elasticity), the hydrodynamic force or the pressure distribution on the face of dam also increases. The maximum effect is obtained when both the dam and the foundation are most flexible. Conversely, when the dam is rigid, foundation flexibility is not so important.

The peak hydrodynamic force is given in Table (2). This table shows that as the flexibility increases, the response also increases.

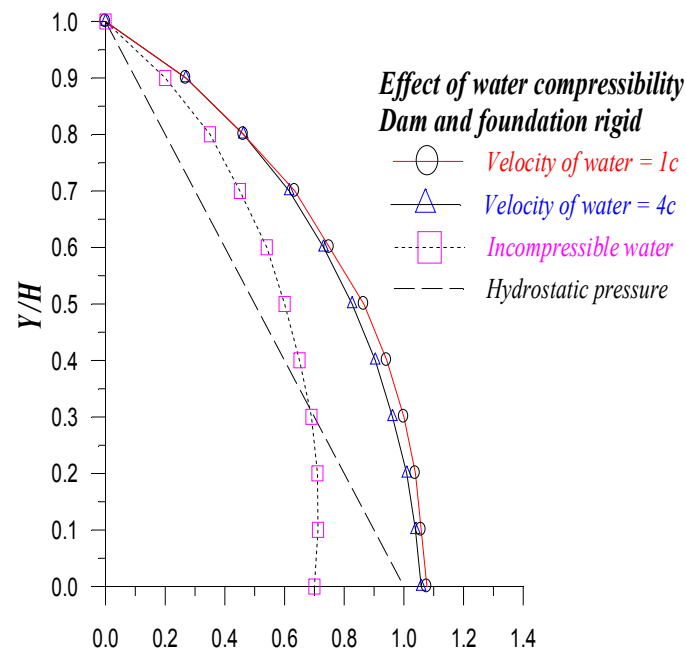

Hydrodynamic/ Hydrostatic pressures $\left(\mathrm{P}_{\mathrm{d}}^{\mathrm{h}} / \mathrm{P}_{\mathrm{s}}\right)$

Figure (3): Effect of water compressibility on hydrodynamic pressure distribution.

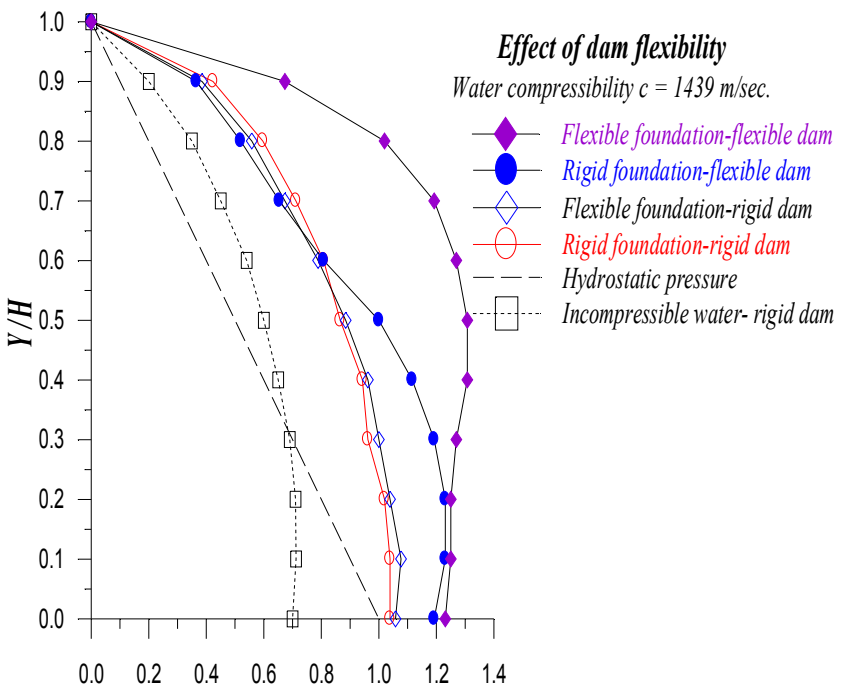

Hydrodynamic/ Hydrostatic pressures $\left(\mathrm{P}_{\mathrm{d}}^{\mathrm{h}} / \mathrm{P}_{\mathrm{s}}\right)$

Figure (4): Effect of dam flexibility on hydrodynamic pressure distribution.

Table (2): Effect of dam flexibility on hydrodynamic pressure distribution due to Heaviside unit base excitation .

\begin{tabular}{|c|c|c|c|c|c|}
\hline \multirow{2}{*}{$\begin{array}{c}\text { Response } \\
\text { Description }\end{array}$} & Fexible Foundation & \multicolumn{4}{|c|}{ Rigid Foundation } \\
\cline { 2 - 6 } & $\overline{\mathrm{E}}=1 \mathrm{E}$ & $\overline{\mathrm{E}}=1 \mathrm{E}$ & $\overline{\mathrm{E}}=2 \mathrm{E}$ & $\overline{\mathrm{E}}=4 \mathrm{E}$ & $\overline{\mathrm{E}}=\infty$ \\
\hline $\mathrm{P}_{\mathrm{d}}^{\mathrm{h}} / \mathrm{P}_{\mathrm{s}}$ & 1.360 & -- & 0.505 & 0.500 & 0.395 \\
\hline
\end{tabular}




\subsubsection{Effect of Earthquake Excitation}

Three different earthquakes each with different ground motion characteristics are considered as shown in Figures (5a-e).

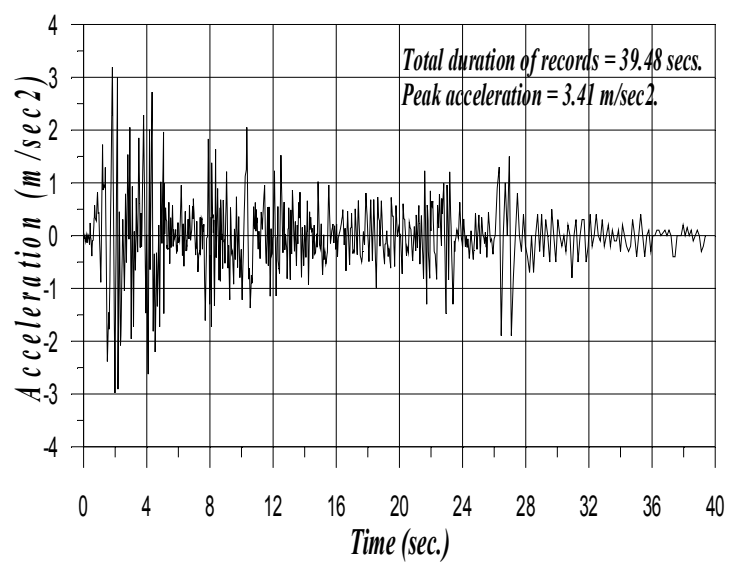

(a) Transverse component of El-Centro earthquake of May 1940.

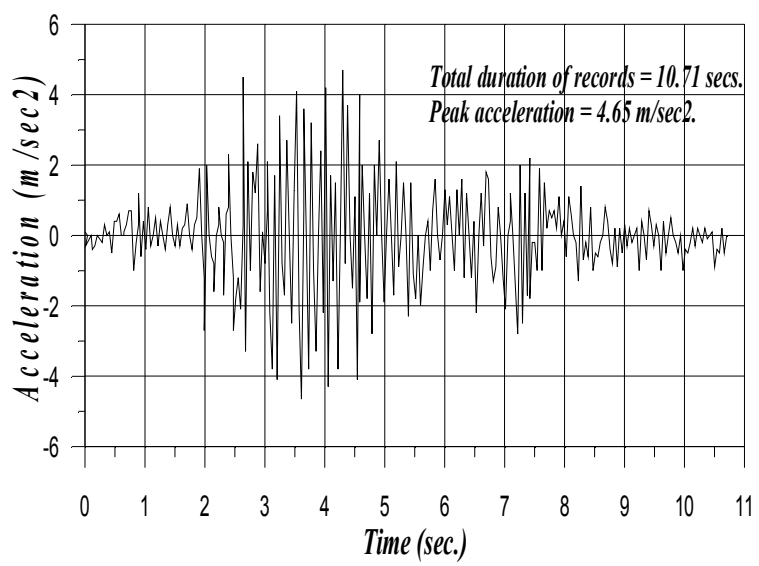

(c) Transverse component of Koyna earthquake of Dec., 1967.

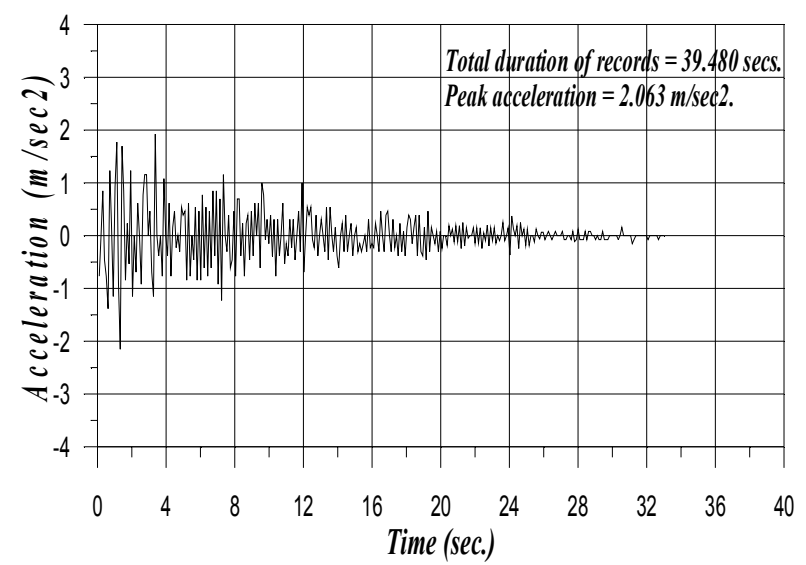

(b) Vertical component of El-Centro earthquake of May 1940.

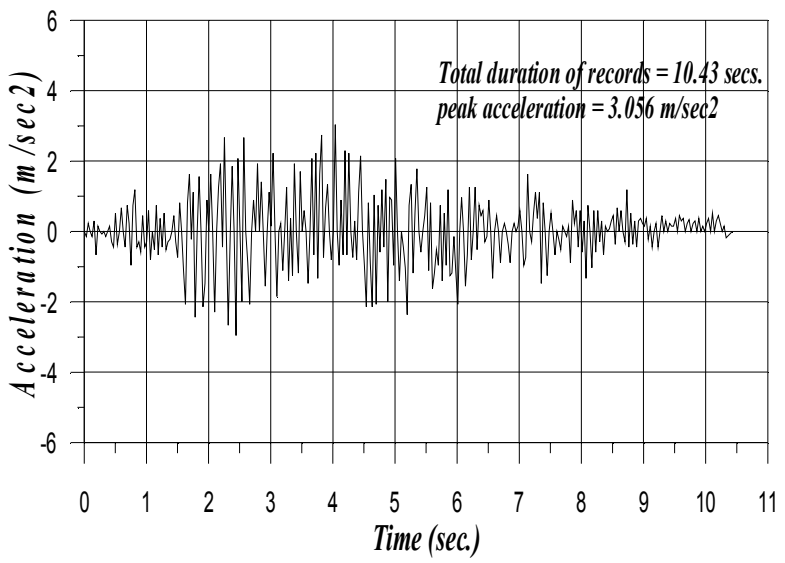

(d) Vertical component of Koyna earthquake of Dec., 1967.

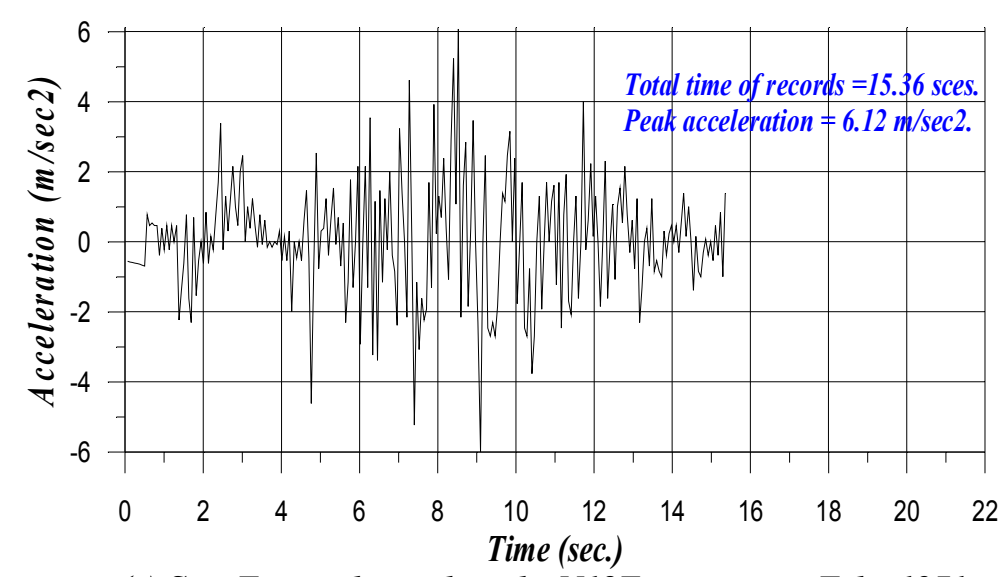

(e) San-Fernando earthquake N18E component Feb., 1971.

Figure (5): Earthquakes (from Paul, [20]). 
The undamped response ( $0 \%$ damping) of the crest displacement, the stress at the dam heel and the hydrodynamic pressure at the base of the dam when subjected to both transverse and vertical components of either the El-Centro or Koyna or San Fernando earthquakes, simultaneously are shown in Figures (6), (7) and (8), respectively. It is noticed that the response characteristics are very much dependent on the type of earthquake excitation. This is because of the strong interaction between the impounded water and the foundation when the vertical component of the earthquake is considered in comparison with that due to only the transverse component of earthquake. The peak responses of the dam for various earthquake (transverse and vertical) excitations are summarized in Table (3).

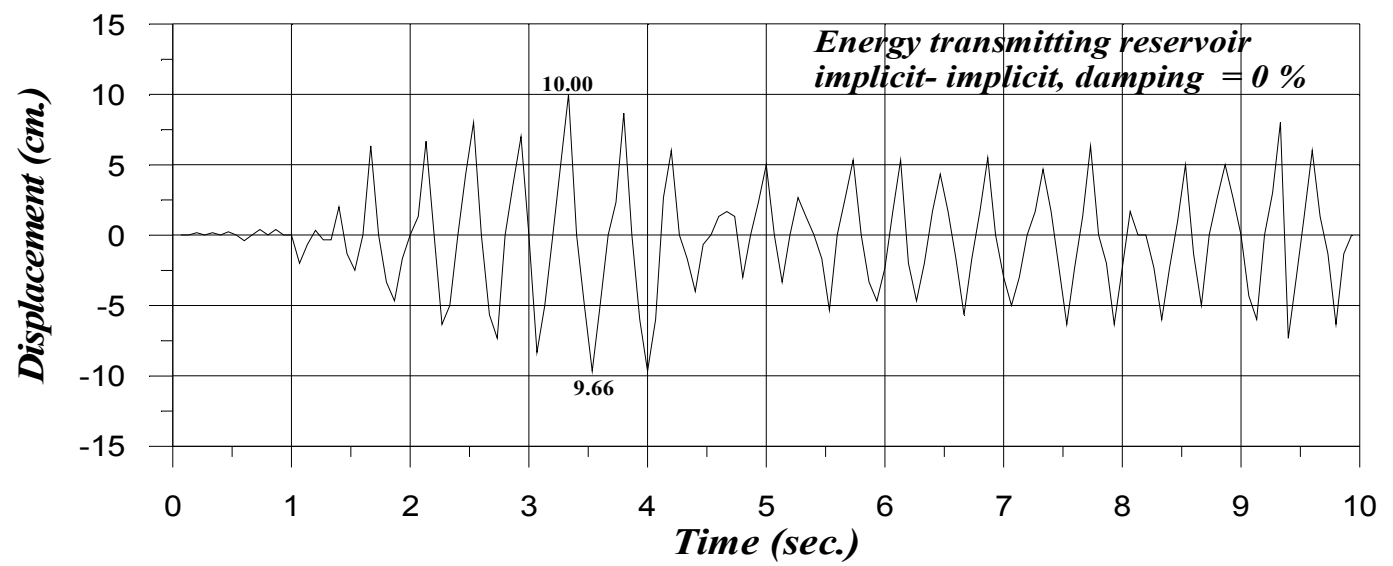

(a) El-Centro earthquake.

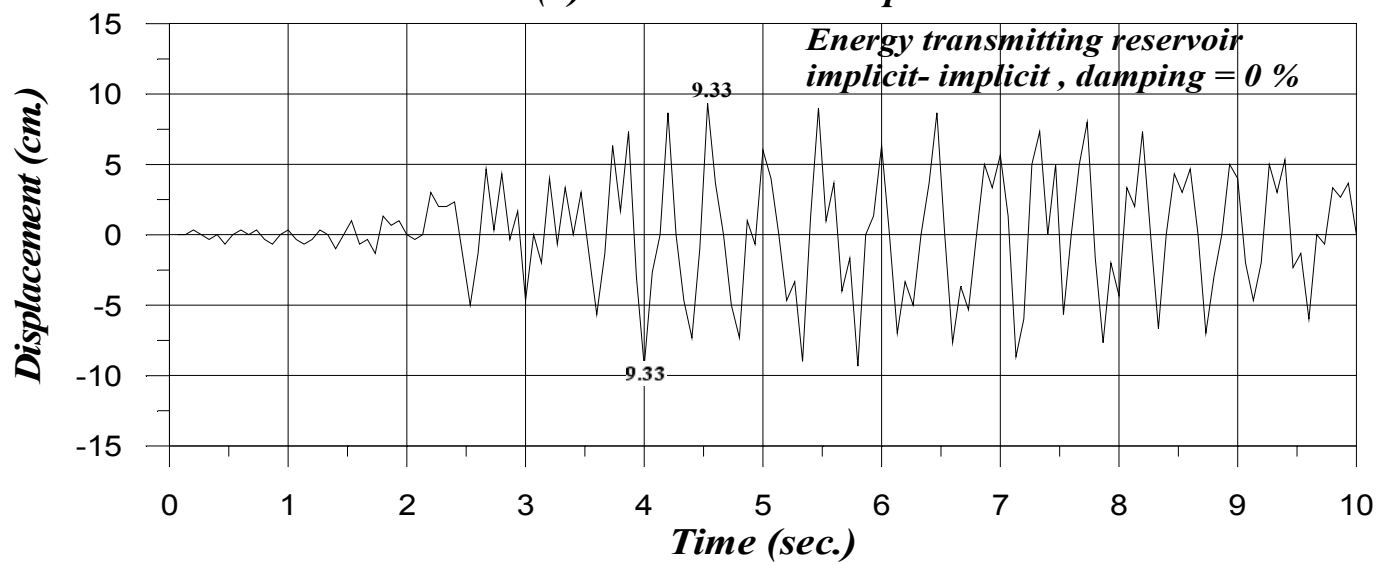

(b) Koyna earthquake.

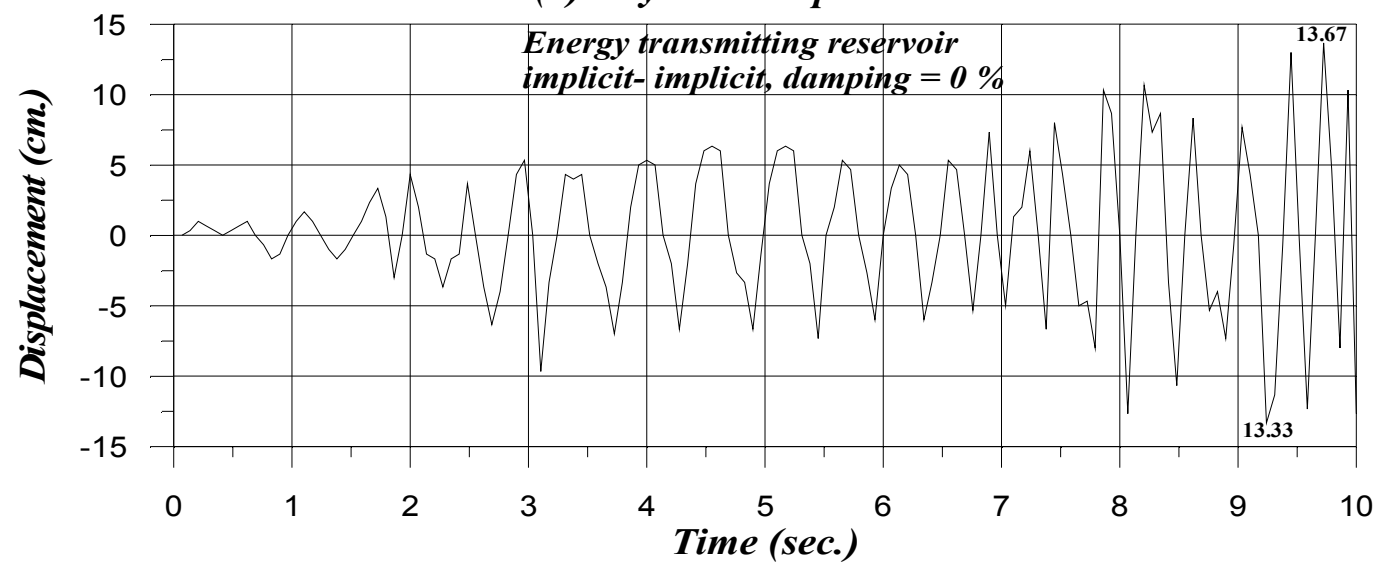

(c) San-Fernando earthquake.

Figure (6): Response of dam crest displacement when subjected to various earthquake ( transverse and vertical) excitations. 


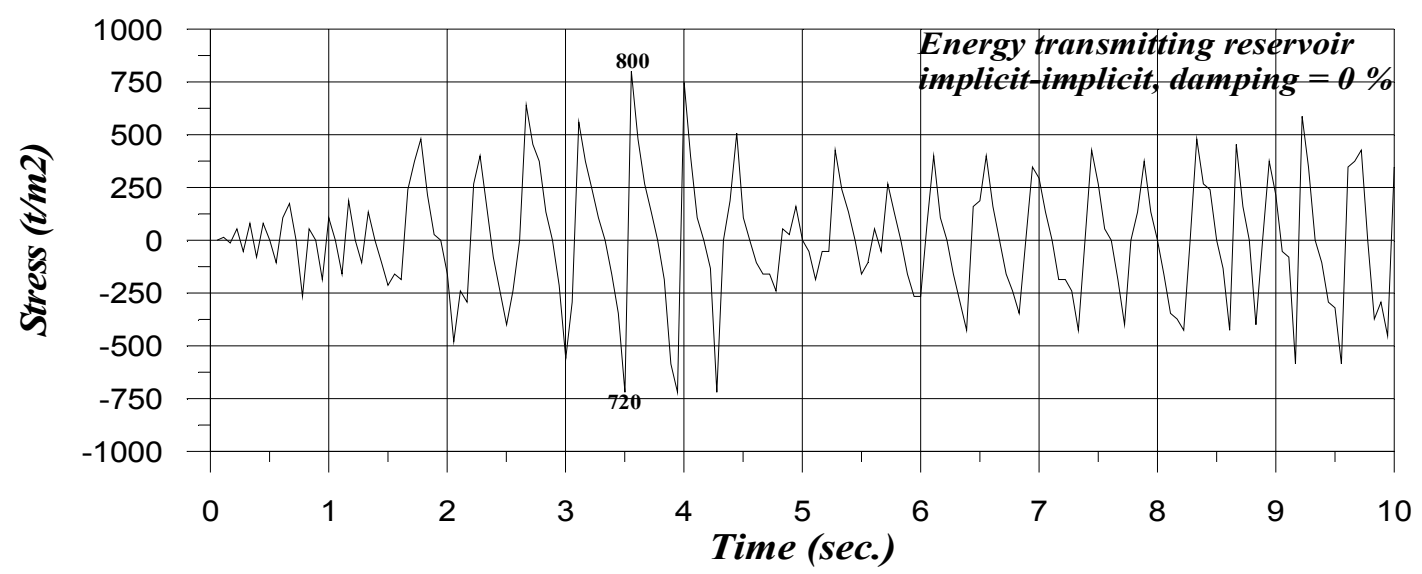

(a) El-Centro earthquake.

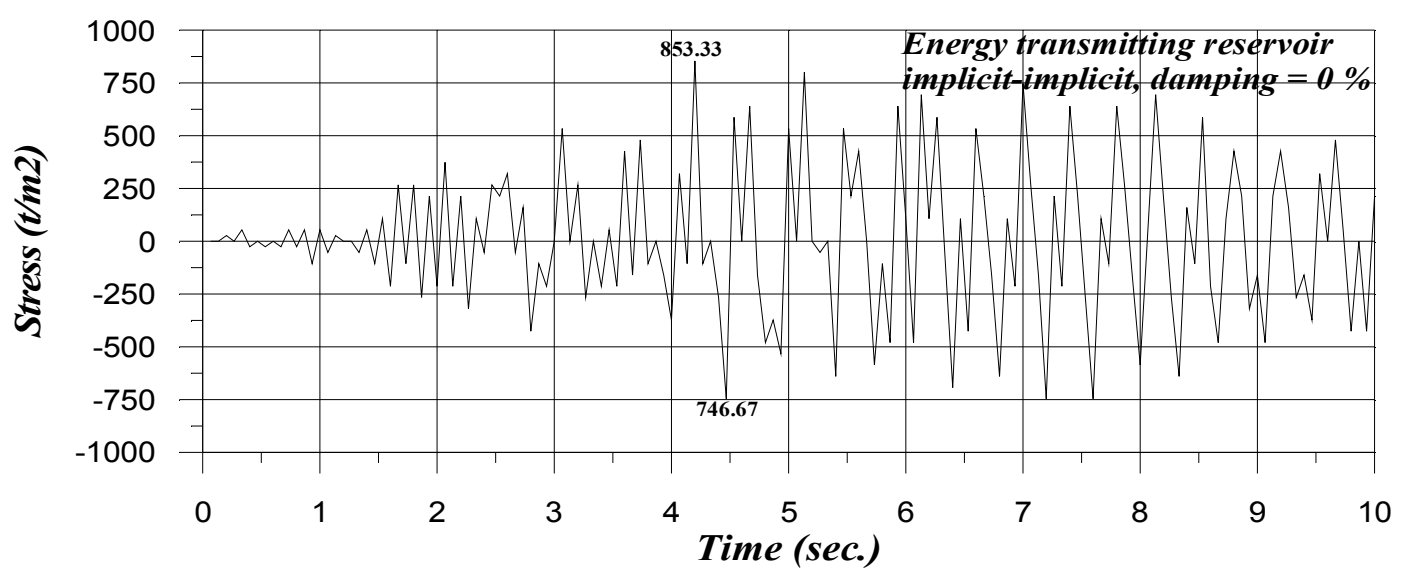

(b) Koyna earthquake.

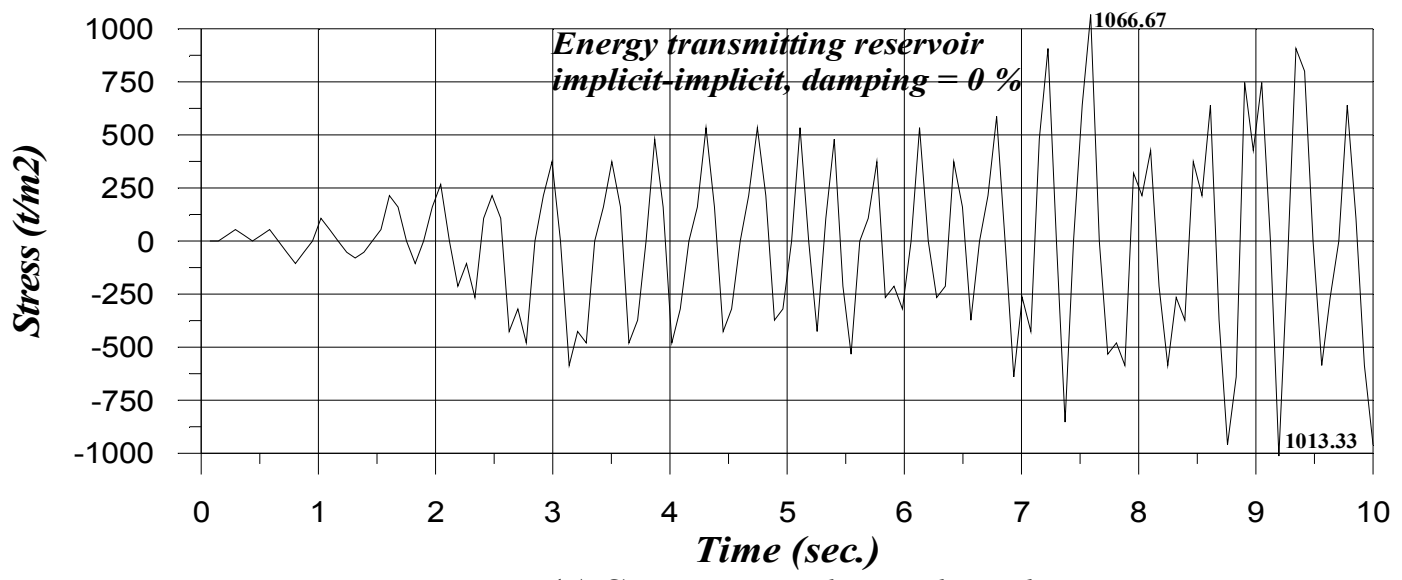

(c) San-Fernando earthquake.

Figure (7): Response of normal stress at the dam heel when subjected to various earthquake (transverse and vertical) excitations. 


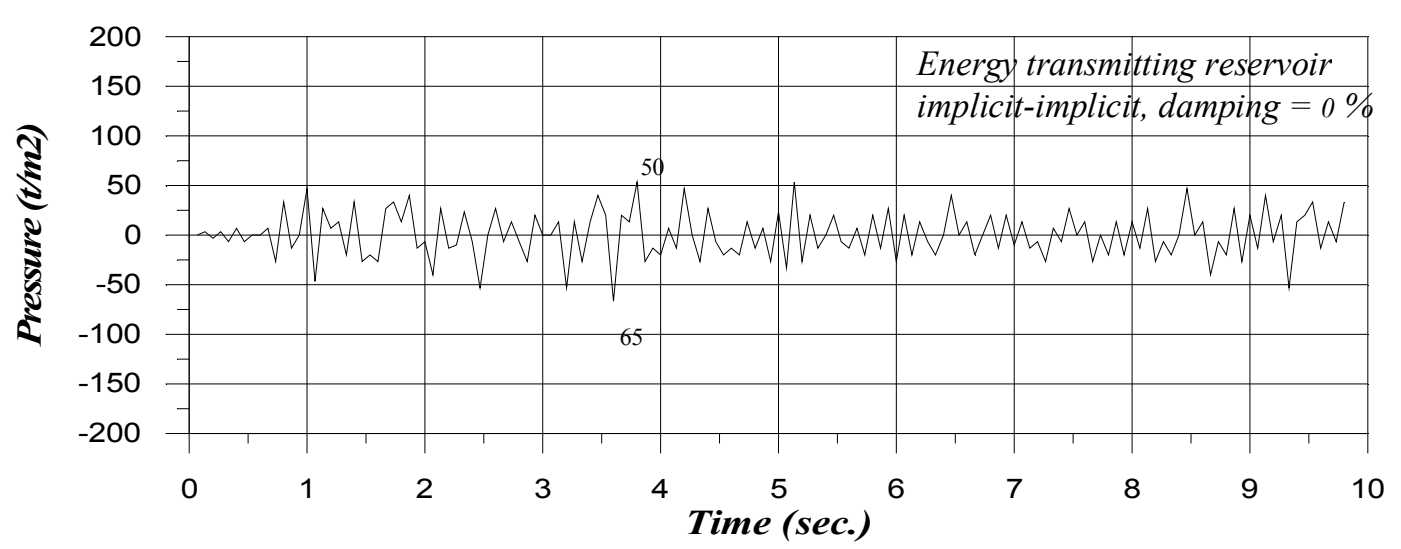

(a) El-Centro earthquake.

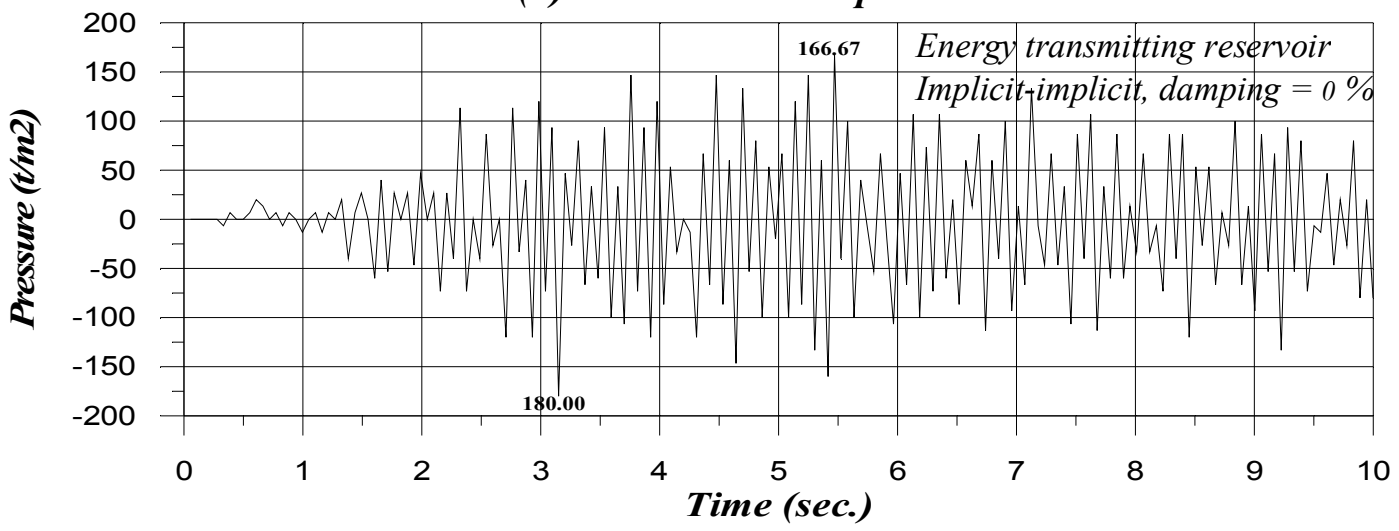

(b) Koyna earthquake.

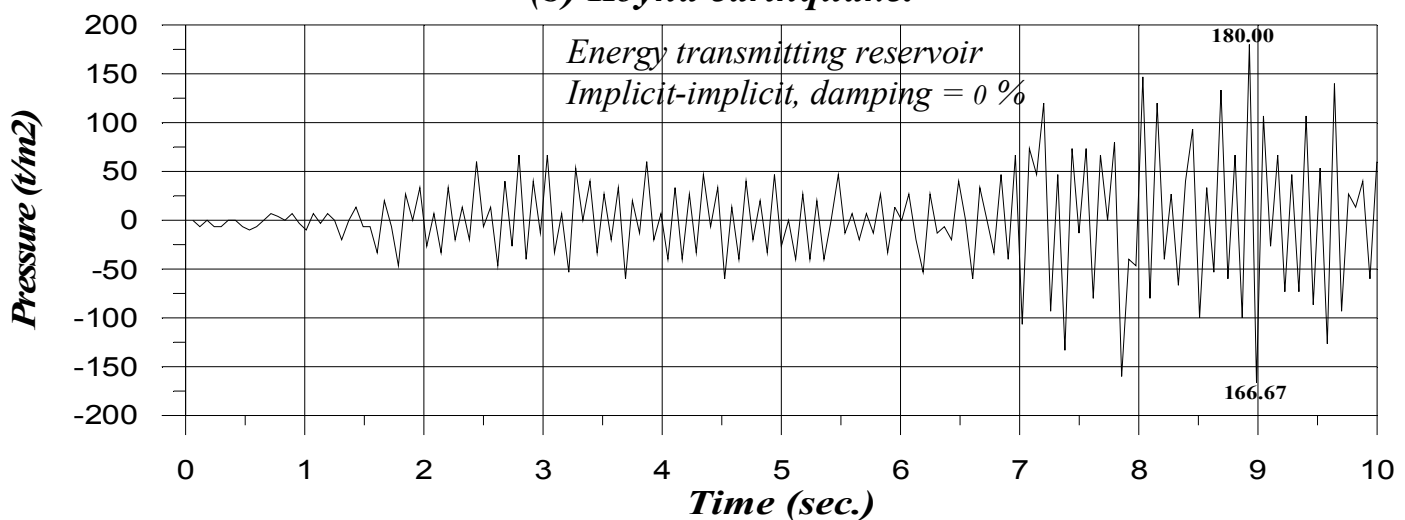

(c) San-Fernando earthquake.

Figure (8): Response of pressure at the dam base when subjected to various earthquake (transverse and vertical) excitations.

Table (3): Comparison of peak responses of dam for various earthquake (transverse and vertical) excitations.

\begin{tabular}{|c|c|c|c|c|c|c|}
\hline $\begin{array}{c}\text { Response } \\
\text { Description }\end{array}$ & \multicolumn{2}{|c|}{$\begin{array}{c}\text { El-Centro } \\
\text { Earthquake }\end{array}$} & \multicolumn{2}{c|}{$\begin{array}{c}\text { Koyna } \\
\text { Earthquake }\end{array}$} & \multicolumn{2}{c|}{$\begin{array}{c}\text { San-Fernando } \\
\text { Earthquake }\end{array}$} \\
\hline Dam crest displacement & 10.00 & -9.66 & 9.33 & -9.33 & 13.67 & -13.67 \\
$(\mathrm{~cm})$ & $a t$ & $a t$ & $a t$ & $a t$ & $a t$ & at \\
& $3.33 \mathrm{sec}$. & $3.53 \mathrm{sec}$. & $4.53 \mathrm{sec}$. & $4.00 \mathrm{sec}$. & $9.72 \mathrm{sec}$. & $9.24 \mathrm{sec}$. \\
\hline Stress at the dam heel & 800 & -720 & 853.33 & -746.67 & 1066.67 & -1013.33 \\
$\left(T / \mathrm{m}^{2}\right)$ & $a t$ & $a t$ & $a t$ & $a t$ & $a t$ & at \\
& $3.55 \mathrm{sec}$. & $3.50 \mathrm{sec}$. & $4.20 \mathrm{sec}$. & $4.47 \mathrm{sec}$. & $7.59 \mathrm{sec}$. & $9.19 \mathrm{sec}$. \\
\hline Pressure at the Dam base & 50 & -65 & 166.67 & -180.00 & 180.00 & -166.67 \\
$\left(\mathrm{~T} / \mathrm{m}^{2}\right)$ & $a t$ & $a t$ & $a t$ & $a t$ & $a t$ & at \\
& $3.85 \mathrm{sec}$. & $3.60 \mathrm{sec}$. & $5.47 \mathrm{sec}$. & $3.15 \mathrm{sec}$. & $8.92 \mathrm{sec}$. & $8.98 \mathrm{sec}$. \\
\hline
\end{tabular}




\subsubsection{Effect of Structural Damping}

The responses of Koyna dam when subjected to the transverse component of the Koyna earthquake for $0 \%, 5 \%$ and $10 \%$ damping are shown in Figures $(9,10$ and 11), respectively. It is observed that the effect of structural damping is significant and, therefore, estimation of damping in the evaluation of the response should be made carefully. The peak responses of the dam for different damping ratios are given in Table (4).
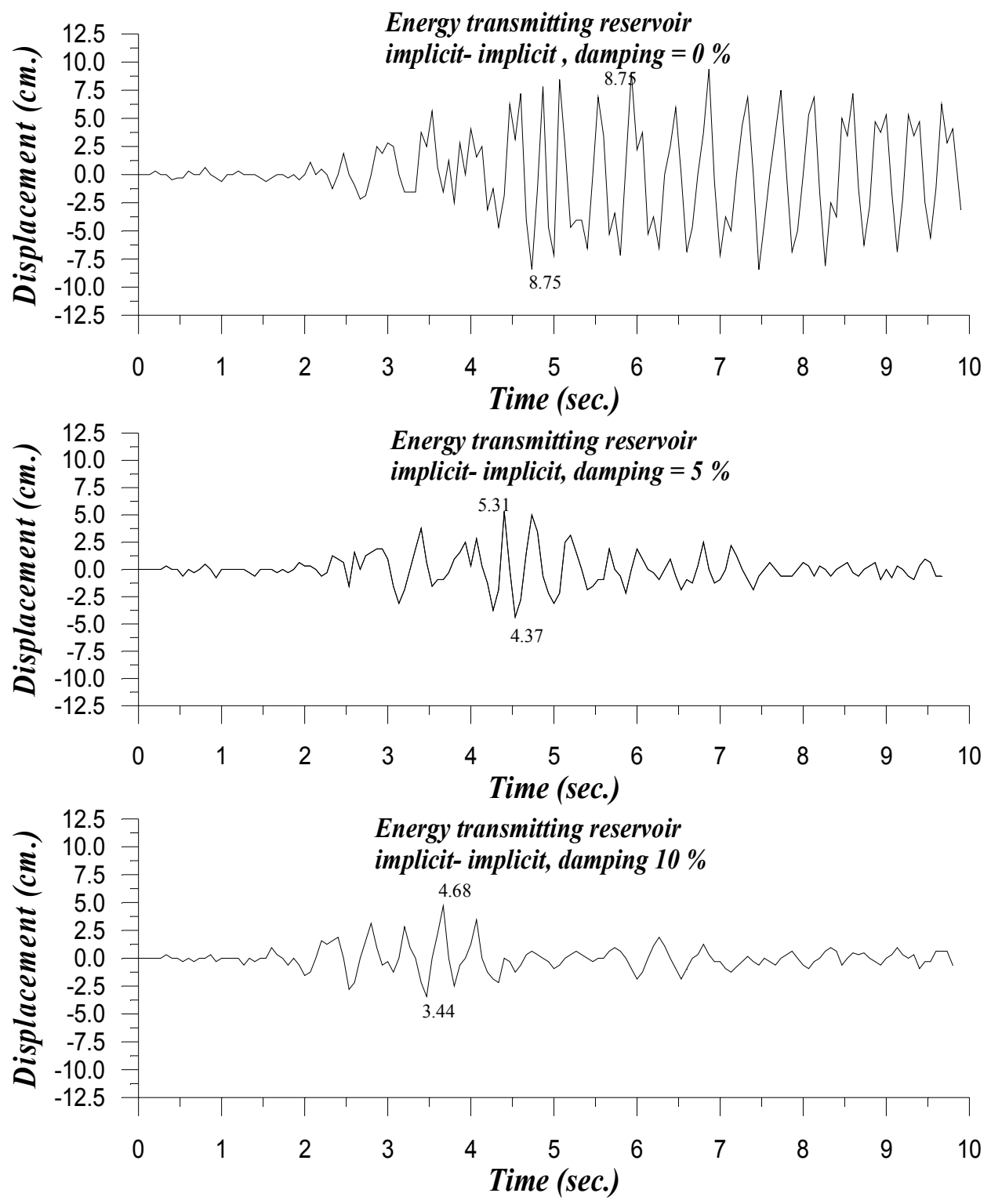

Figure (9): Response of dam crest displacement when subjected to transverse component of Koyna earthquake. 

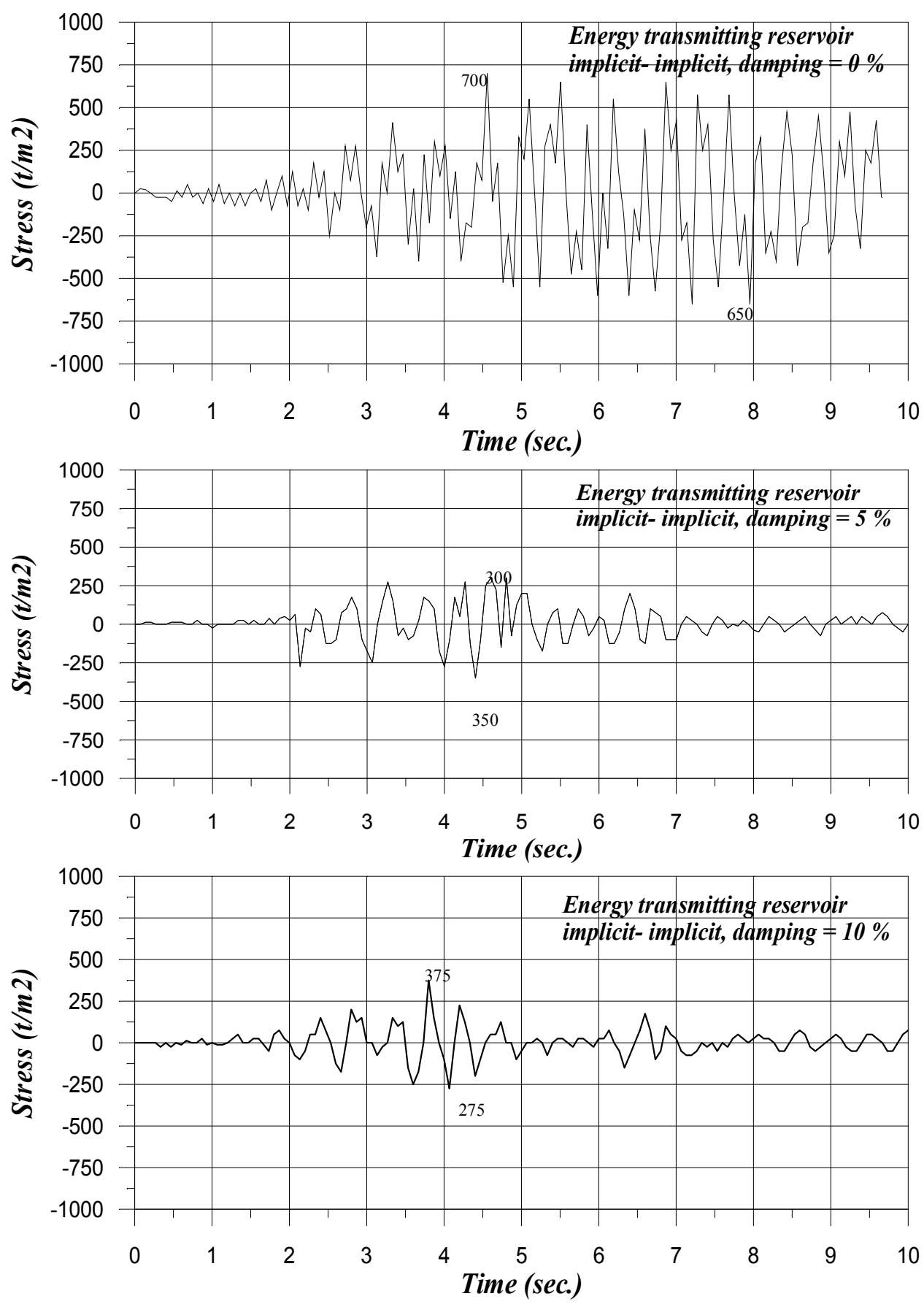

Figure (10): Response of normal stress at the dam heel when subjected to transverse component of Koyna earthquake. 
Al-Damluji: Nonlinear Coupled Finite Element Analysis of A Dam-Reserviour Under -----
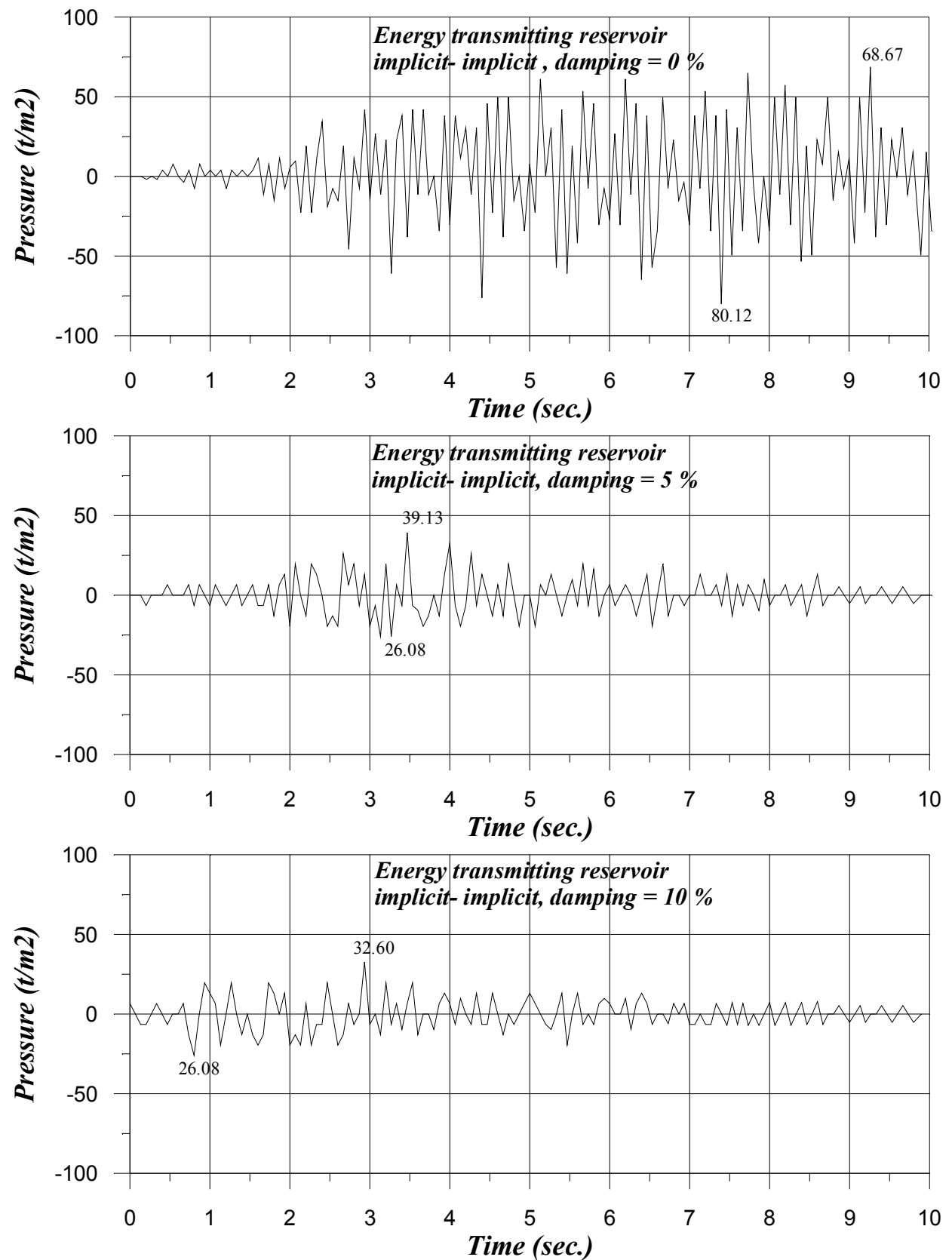

Figure (11): Response of pressure at the dam base when subjected to transverse component of Koyna earthquake.

Table (4): Effect of structural damping on the response of dam when subjected transverse component of Koyna earthquake.

\begin{tabular}{|c|c|c|c|c|c|c|}
\hline Response Description & \multicolumn{2}{|c|}{ 0 \% damping } & \multicolumn{2}{c|}{$\mathbf{5} \%$ damping } & \multicolumn{2}{c|}{$10 \%$ damping } \\
\hline Dam crest displacement & 8.75 & -8.75 & 5.31 & -4.37 & 4.68 & -3.44 \\
$(\mathrm{~cm})$ & $a t$ & $a t$ & $a t$ & $a t$ & at & at \\
& $5.8 \mathrm{sec}$. & $4.8 \mathrm{sec}$. & $4.4 \mathrm{sec}$. & $4.5 \mathrm{sec}$. & $3.66 \mathrm{sec}$. & $3.46 \mathrm{sec}$. \\
\hline Stress at the dam heel & 700 & -650 & 300 & -350 & 375 & -275 \\
$\left(\mathrm{~T} / \mathrm{m}^{2}\right)$ & $a t$ & $a t$ & $a t$ & at & at & at \\
& $4.55 \mathrm{sec}$. & $7.95 \mathrm{sec}$. & $4.6 \mathrm{sec}$. & $4.4 \mathrm{sec}$. & $3.8 \mathrm{sec}$. & $4.07 \mathrm{sec}$. \\
\hline Pressure at the Dam base & 68.67 & -80.12 & 39.13 & -26.08 & 32.60 & -26.08 \\
$\left(\mathrm{~T} / \mathrm{m}^{2}\right)$ & at & at & at & at & at & at \\
& $9.26 \mathrm{sec}$. & $7.4 \mathrm{sec}$. & $3.5 \mathrm{sec}$. & $3.26 \mathrm{sec}$. & $2.93 \mathrm{sec}$. & $0.8 \mathrm{sec}$. \\
\hline
\end{tabular}




\subsubsection{Effect of Material Nonlinearity}

The nonlinear response of Koyna dam when subjected to transverse and vertical Koyna earthquake is shown in Figure (12). The concrete and foundation-rock-soil are represented by the Drucker-Parger yield criterion. The yield stress values of the concrete and the foundation rock are taken equal to be $323.94 \mathrm{~T} / \mathrm{m}$ and $257.75 \mathrm{~T} / \mathrm{m}$, respectively. It is found that the effect of material nonlinearity is significant and when the nonlinearity in the dam structure is considered, the response reduces appreciably.

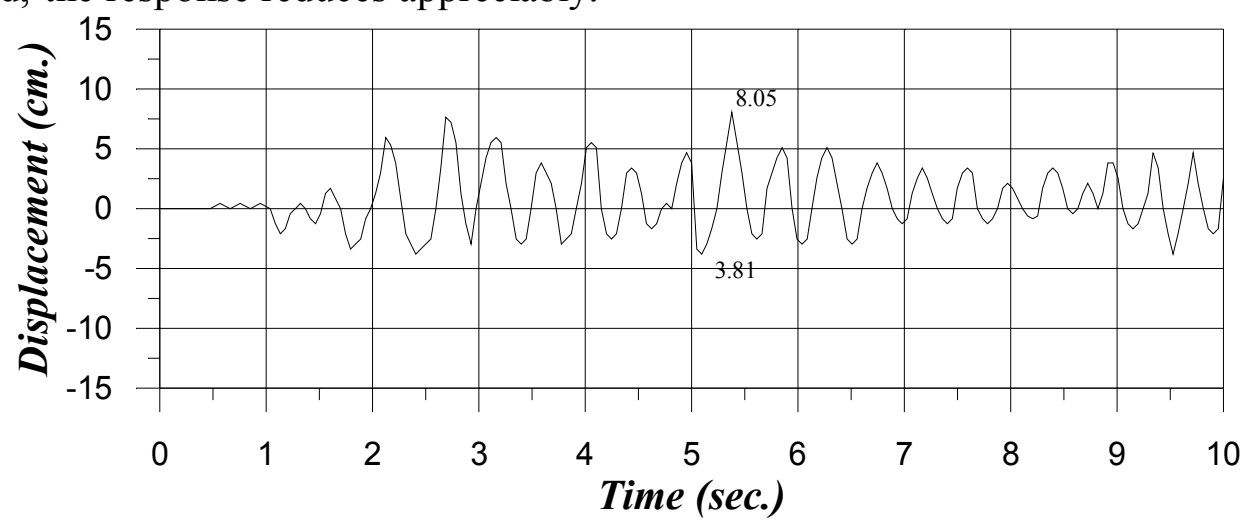

(a) Response of dam crest displacement.

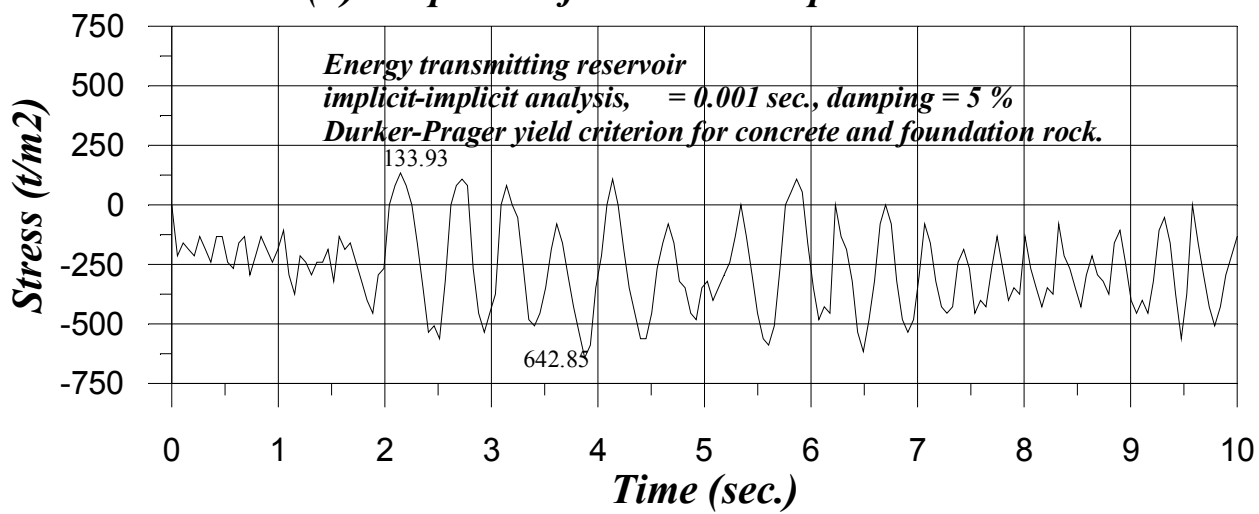

(b) Response of normal stress at the dam heel.

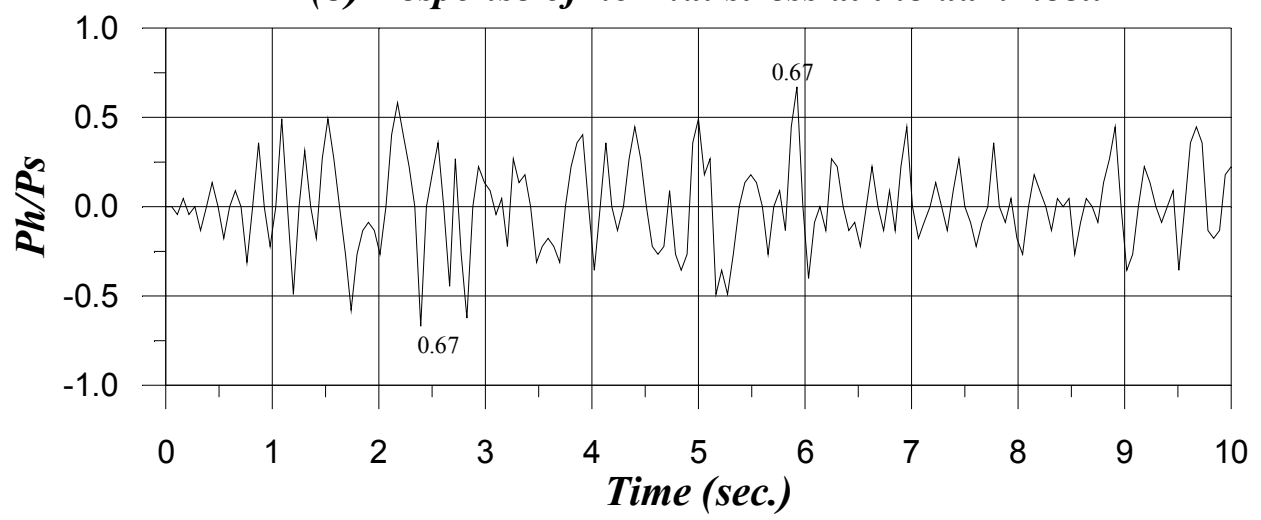

(c) Response of hydrodynamic force on dam.

Figure (12): Nonlinear response of dam when subjected to transverse and vertical components of Koyna earthquake. 


\section{Conclusions}

From this limited investigation the followings can be drawn:

1. The computer code developed was found to be very useful and can be used for wide range of applications in many soil-fluid-structure interaction problems.

2. The partitioned solution scheme in which the fluid, structure and soil-pore fluid is integrated in staggered fashion was found to be very efficient.

3. Two-phase materials subjected to dynamic loading can be formulated with approximate numerical solutions and acceptable degree of accuracy.

4. Analysis of the actual behavior of constructions during dynamic loading exemplify the fact that the soil-structure interaction and, in the case of hydraulic structures, the fluidstructure interaction are phenomena which may have an important influence on the structural seismic response.

5. The compressibility of water has a significant effect on the distribution of pressure on the rigid dam.

6. As the flexibility of the dam system increases, the pressure distribution on the face of dam also increases. The maximum effect is obtained when both the dam and the foundation are most flexible. Conversely, when the dam is rigid, foundation flexibility is not so important.

7. The response characteristics of the dam-reserviour are very much dependent on the type of earthquake excitation, structural damping and material nonlinearity.

\section{References}

1. Aslam, M., (1981), "Finite Element Analysis of Earthquake-Induced Sloshing in Axi-symmetric Tanks", International Journal of Numerical Methods in Engineering, Volume 17, pp. 159-170.

2. Al-Nu'aimi, R. M. S., (2004), "Nonlinear Analysis of Coupled Soil-Fluid-Structure Interaction Under Dynamic Loading”, Ph.D. Thesis, University of Baghdad, Iraq.

3. Biot, M. A., (1941),"General Theory for Three-Dimensional Consolidation", Journal of Applid Physics, Volume 12, pp. 155-164.

4. Biot, M. A., (1955), "Theory of Elasticity and Consolidation for a Porous Anisotropic Solid", Journal of Applid Physics, Volume 26, pp. 182-185.

5. Chopra, A., Wilson, E., and Farhoomand, I., (1969), "Earthquake Analysis of Reservoir-Dam Systems", Proceedings of the $4^{\text {th }}$ World Conference on Earthquake Engineering, Santiago, Chile.

6. Everstine, G. C., and Henderson, F. M., (1990), "Coupled Finite Element Boundary Element Approach for Fluid Structure Interaction", Journal of the Acoustical Society of America, Volume 87, No. 5, pp. 1938-1947.

7. Feng, Y. Q., and Quevat, J. P., (1990),"3-Dimensional Non-Linear Fluid-Structure Interaction Problems-Formulation by the Finite and Infinite Element Methods", International Journal for Numerical Methods in Engineering, Volume 30, No. 6, October, pp. 1115-1128.

8. Frank, M. W., (1994), "Fluid Mechanics", Third Edition, McGRAW-Hill, Inc., Chapters 8 and 9.

9. Guan, F., and Moore, I. D., (1997), "New Techniques for Modelling Reservoir-Dam and Foundation-Dam Interaction", Journal of Soil Dynamics and Earthquake Engineering, Volume 16, pp. 285-293.

10. Jeans, R. A., and Mathews, I. C., (1990)," Solution of Fluid-Structure Interaction Problems Using a Coupled Finite Element and Variational Boundary Element Technique", Journal of the Acoustical Society of America, Volume 88, No. 5, November, pp. 2459-2466.

11. Joseph, H. S., (1997), "Fluid Mechanics", Springer, Chapters 2 and 3.

12. Kock, E., and Olson, L., (1991),"Fluid Structure Interaction Analysis by the Finite Element Method- a Variational Approach", International Journal for Numerical Methods in Engineering, 
Volume 31, No. 3, March, pp. 463-491.

13. Lui, A., and Lou, J., (1990), "Dynamic Coupling of A Liquid-Tank System Under Transient Excitations", Journal of Ocean Engineering, Volume 17, No. 3, pp. 263-277.

14. Nitikitpaiboon, C., and Bathe K. J., (1993)," An Arbitrary Lagrangian-Eulerian Velocity Potential Formulation for Fluid Structure Interaction", Journal of Computers and Structures, Volume 47, No. 4-5, June, pp. 871-891.

15. Nogami, T., and Kazama, M., (1997), "Thin Layer Element Method for Dynamic Soil-Structure Interaction Analysis of Axi-Symmetric Structure in Submerged Soil”, Journal of Soil Dynamics and Earthquake Engineering, Volume 16, pp. 337-351.

16. Olson, L. G., and Bathe, K. J., (1983), "A Study of Displacement-Based Fluid Finite Elements For Calculating Frequencies of Fluid and Fluid-Structure Systems", Journal of Nuclear Engineering and Design, Volume 76, pp. 137-151.

17. Olson, L. G., and Bathe, K. J., (1985),"Analysis of Fluid-Structure Interactions. A Direct Symmetric Coupled Formulation Based on the Fluid Velocity Potential", Journal of Computers and Structures, Volume 21, No. 12, December, pp. 21-32.

18. Park, K.C., and Felippa, C. A., (1984), "Recent Developments in Coupled Field analysis Methods", Chapter 11, Numerical Methods in Coupled Systems (edited by R. W. Lewis, P. Bettes, and E. Hinton, John Wiley \& Sons), pp. 327-351.

19. Pastor, M., Li, T., and Merodo J. A. F., (1997), "Stabilized Finite Elements for Harmonic Soil Dynamics Problems Near the Undrained-Incompressible Limit", Journal of Soil Dynamics and Earthquake Engineering, Volume 16, pp. 161-171.

20. Paul, D. K., (1982), "Efficient Dynamic Solutions for Single and Coupled Multiple Field Problems", Ph.D. Thesis, University College, Swansea.

21. Rajasankar, J., Iyer, N.R., and Rao, T., (1993), "A New 3-D Finite Element Model to Evaluate Added Mass for Analysis of Fluid-Structure Interaction Problems", International Journal for Numerical Methods in Engineering, Volume 36, No. 6, March, pp. 997-1012.

22. Sauve, R. G., Morandin, G. D., and Nadeau, E., (1993),"Impact Simulation of Liquid-Filled Containers Including Fluid-Structure Interaction .1. Theory", Journal of Pressure Vessel Technology, Transactions of the ASME, Volume 115, No. 1, February, pp.68-72.

23. Sauve, R. G., Morandin, G. D., and Nadeau, E., (1993), "Impact Simulation of Liquid-Filled Containers Including Fluid-Structure Interaction .2. Experimental Verification", Journal of Pressure Vessel Technology, Transactions of the ASME, Volume 115, No. 1, February, pp.7379.

24. Seybert, A. F., Wu, T. W., and Li, W. L., (1993), "A Coupled FEM BEM for Fluid-Structure Interaction using Ritz Vectors and Eigenvectors", Journal of Vibration and Acoustics, Transactions of the ASME, Volume 115, No. 2, April, pp. 152-158.

25. Shawky, A. and Maekawa, K., (1996), "Nonlinear Response of Underground RC Structures Under Shear", Journal of Material, Concrete Structures and Pavements, JSCE, Volume 31, 538, pp. 195-206.

26. Simon, B. R., Wu, J. S. S., Zienkiewicz, O. C. and Paul, D. K., (1986), "Evaluation of $u$-w and $u-\pi$ Finite Element Methods for the Dynamic Response of Saturated Porous Media Using OneDimensional Models", International Journal for Numerical and Analytical Methods in Geomechanics, Volume10, pp.461-482.

27. Spyrakos, C. C., and Xu, C., (1997), "Soil-Structure-Water Interaction of Intake-Outlet Towers Allowed to Uplift", Journal of Soil Dynamics and Earthquake Engineering, Volume 16, pp. 151159.

28. Wilson, E., and Khalvati, M., (1983), "Finite Elements For the Dynamic Analysis of Fluid-Solid Systems", International Journal of Numerical Methods in Engineering, Volume 19, pp. 16571668.

29. Zeng, X. G., Bielak J., and MacCamy, R. C., (1992), "Stable Variational Coupling Method for Fluid-Structure Interaction in Semi-infinite Media", Journal of Vibration and Acoustics, Transactions of the ASME, Volume 114, No. 3, July, pp. 387-396. 
30. Zienkiewicz, O. C., (1984), "Coupled Problems and Their Numerical Solution”, Chapter One, Numerical Methods in Coupled Systems (edited by R. W. Lewis, P. Bettess, and E. Hinton, John Wiley \& Sons), pp. 35-58.

31. Zienkiewicz, O. C., and Bettess, P., (1982), "Soils and other Saturated Media under Transient, Dynamic Conditions: General formulation and the Validity of the Various Simplifying Assumptions", in Soil Mechanics: Transient and Cyclic Loads, Edited by G. N. Pande and O. C. Zienkiewicz, Wiley New York, Chapter One.

32. Zienkiewicz, O. C. and Taylor, R. L., (2000), "The Finite Element Method", Fifth edition Published by Butterworth-Heinemann, Volume 3: Fluid Dynamics.

33. Zienkiewicz, O. C., and Shiomi, T., (1984), "Dynamic Behaviour of Saturated Porous Media: The Generalized Biot Formulation and Its Numerical Solution”, Journal of Numerical Analytical Methods in Geomechanics, Volume 8, pp.71-96.

34. Zienkiewicz, O. C., Bettess, P. and Kelly, D. W., (1978), "The Finite Element Method for Determining Fluid Loading on Rigid Structures, Two-and Three Dimensional Formulations", Numerical Methods in Offshore Engineering, Chapter Four, edited by O. C. Zienkiewicz, et al., John Wiley and Sons, pp. 141-184.

35. Zienkiewicz, O. C., Chan, A. H. C., Pastor, M., Paul, D. K., and Shiomi, T., (1990), "Static and Dynamic Behaviour of Soils: A Rational Approach to Quantitative Solutions. I Fully Saturated Problems", Proceedings of the Royal Society of London, Volume 429, pp.285-309.

36. Zienkiewicz, O. C., Xie, Y. M., Scherefler, B. A., Ledesma, A., and Bicanic, N., (1990), "Static and Dynamic Behaviour of Soils: A Rational Approach to Quantitative Solutions. II SemiSaturated Problems", Proceedings of the Royal Society of London, Volume 429, pp.311-321.

The work was carried out at the college of Engineering. University of Baghdad 